US Army Corps

of Engineers.

Prepared for the U.S. Army Corps of Engineers, Portland District,

under an Interagency Agreement with the U.S. Department of Energy

Contract DE-AC05-76RL01830

\title{
Surgically Implanted JSATS Micro- Acoustic Transmitters Effects on Juvenile Chinook Salmon and Steelhead Tag Expulsion and Survival, 2010
}

$\begin{array}{ll}\text { CM Woodley } & \text { KM Knox } \\ \text { SM Carpenter } & \text { J Kim } \\ \text { KM Carter } & \text { ME Gay } \\ \text { KA Wagner } & \text { MA Weiland } \\ \text { IM Royer } & \text { RS Brown }\end{array}$

September 2011

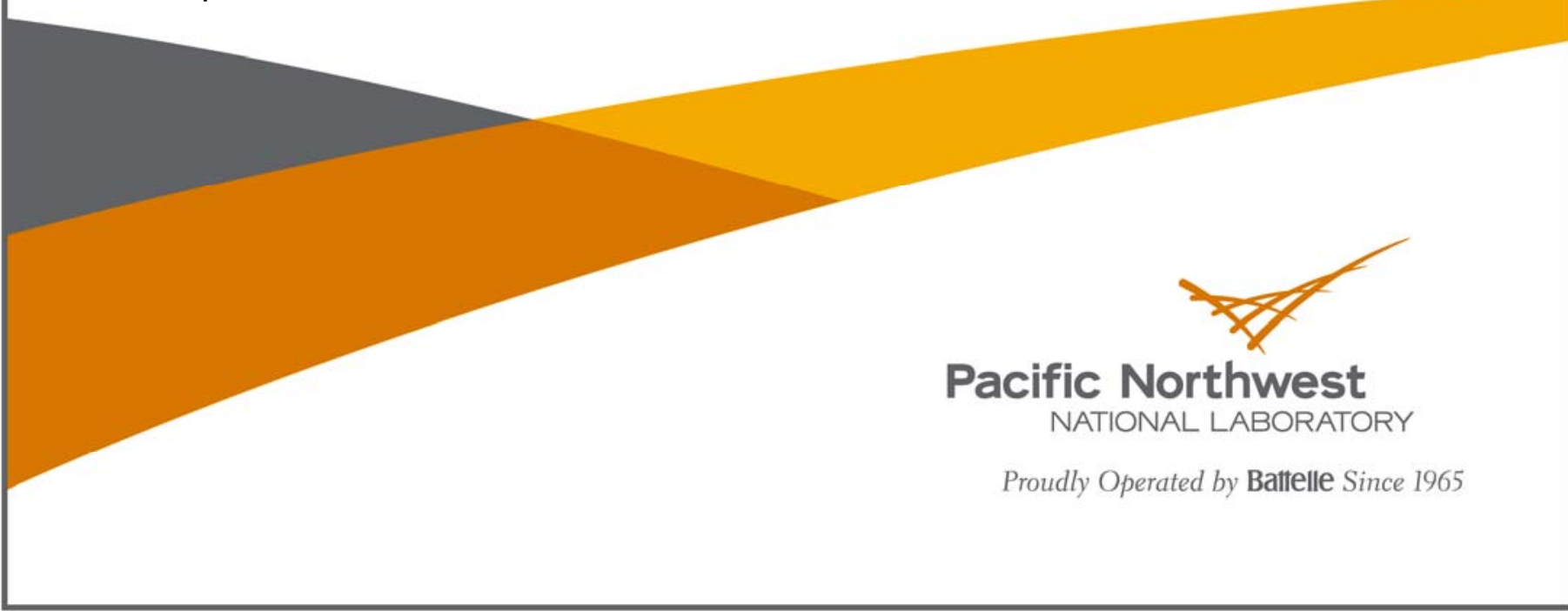




\section{DISCLAIMER}

This report was prepared as an account of work sponsored by an agency of the United States Government. Neither the United States Government nor any agency thereof, nor Battelle Memorial Institute, nor any of their employees, makes any warranty, express or implied, or assumes any legal liability or responsibility for the accuracy, completeness, or usefulness of any information, apparatus, product, or process disclosed, or represents that its use would not infringe privately owned rights. Reference herein to any specific commercial product, process, or service by trade name, trademark, manufacturer, or otherwise does not necessarily constitute or imply its endorsement, recommendation, or favoring by the United States Government or any agency thereof, or Battelle Memorial Institute. The views and opinions of authors expressed herein do not necessarily state or reflect those of the United States Government or any agency thereof.

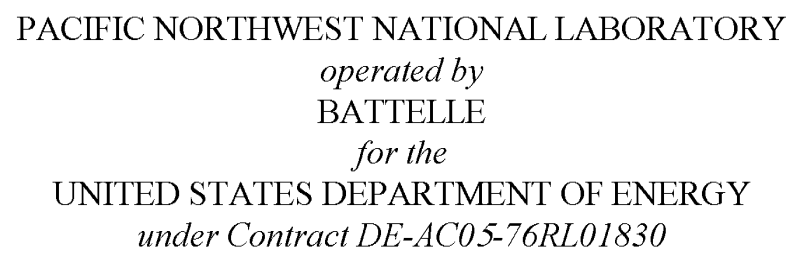

Printed in the United States of America

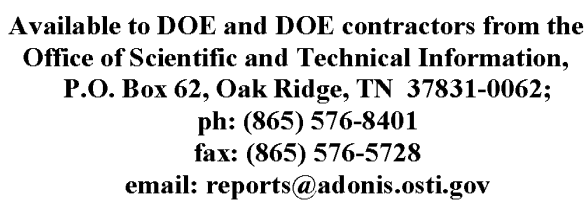

Available to the public from the National Technical Information Service, U.S. Department of Commerce, 5285 Port Royal Rd., Springfield, VA 22161 ph: (800) 553-6847 fax: $(703) 605-6900$ email: orders@ntis.fedworld.gov online ordering: http://www.ntis.gov/ordering.htm

This document was printed on recycled paper. 


\section{Surgically Implanted JSATS Micro- Acoustic Transmitters Effects on Juvenile Chinook Salmon and Steelhead Tag Expulsion and Survival, 2010}

$\begin{array}{ll}\text { CM Woodley } & \text { KM Knox } \\ \text { SM Carpenter } & \text { J Kim } \\ \text { KM Carter } & \text { ME Gay } \\ \text { KA Wagner } & \text { MA Weiland } \\ \text { IM Royer } & \text { RS Brown }\end{array}$

Final Report

September 2011

Prepared for

the U.S. Department of Energy

under Contract DE-AC05-76RL01830

Pacific Northwest National Laboratory

Richland, Washington 99352 



\section{Executive Summary}

The purpose of this study was to evaluate survival model assumptions associated with a concurrent study-Acoustic Telemetry Evaluation of Dam Passage Survival and Associated Metrics at John Day, The Dalles, and Bonneville Dams, 2010 by Thomas Carlson and others in 2010 - in which the Juvenile Salmonid Acoustic Telemetry System (JSATS) was used to estimate the survival of yearling and subyearling Chinook salmon (Oncorhynchus tshawytscha) and steelhead (O. mykiss) migrating through the Federal Columbia River Power System (FCRPS). The micro-acoustic transmitter used in these studies is the smallest acoustic transmitter model to date $(12 \mathrm{~mm}$ long $\times 5 \mathrm{~mm}$ wide $\times 4 \mathrm{~mm}$ high, and weighing $0.43 \mathrm{~g}$ in air). This study and the 2010 study by Carlson and others were conducted by researchers from the Pacific Northwest National Laboratory and the University of Washington for the U.S. Army Corps of Engineers, Portland District, to meet requirements set forth by the 2008 FCRPS Biological Opinion.

In 2010, we compared survival, tag burden, and tag expulsion in five spring groups of yearling Chinook salmon (YCH) and steelhead (STH) and five summer groups of subyearling Chinook salmon (SYC) to evaluate survival model assumptions described in the concurrent study. Each tagging group consisted of approximately $120 \mathrm{fish} / \mathrm{species,} \mathrm{which} \mathrm{were} \mathrm{collected} \mathrm{and} \mathrm{implanted} \mathrm{on} \mathrm{a} \mathrm{weekly} \mathrm{basis,}$ yielding approximately 600 fish total/species. YCH and STH were collected and implanted from late April to late May (5 weeks) and SYC were collected and implanted from mid-June to mid-July (5 weeks) at the John Day Dam Smolt Monitoring Facility. The fish were collected once a week, separated by species, and assigned to one of three treatment groups: 1) Control (no surgical treatment), 2) Sham (surgical implantation of only a passive integrated transponder [PIT] tag), and 3) Tagged (surgical implantation of JSATS micro-acoustic transmitter [AT] and PIT tags). The test fish were held for 30 days in indoor circular tanks at the Bonneville Dam Juvenile Monitoring Facility.

Overall mortality ranged weekly from 45 to $72 \%$ for $\mathrm{YCH}, 55$ to $83 \%$ for $\mathrm{STH}$, and 56 to $84 \%$ for SYC. The high background mortality in all groups and species made it difficult to discern tag effects. However, for $\mathrm{YCH}, \mathrm{STH}$, and SYC, the Tagged treatment groups had the highest overall mean mortality $-62 \%, 79 \%$, and $76 \%$, respectively. Fungal infections were found on $35 \%$ of all fish. Mean tag burden for the Tagged treatment group was relatively low for YCH (1.7\%) and moderate for SYC $(4.2 \%)$, while STH had a very low mean tag burden $(0.7 \%)$. Tag burden was significantly higher in the Tagged treatment group for all species when compared to the Sham treatment group because of the presence of two tags. Surgeon performance did not contribute to the difference in mortality between the Sham and Tagged treatment groups. Tag expulsion from fish that survived to the end of the 30-day experiment was low but occurred in all species, with only two PIT tags and one AT lost, one tag per species.

The high background mortality in this experiment was not limited to a treatment, temperature, or month. The decreased number of surviving fish influenced our experimental results and thus analyses. For future research, we recommend that a more natural exposure to monitor tag effects and other factors, such as swimming ability and predator avoidance, be considered to determine the effects of AT- and PITimplantation on fishes. 



\section{Acknowledgments}

This project was funded by the U.S. Army Corps of Engineers (USACE), Portland, Oregon. We thank Brad Eppard, the USACE contracting officer's representative, for his oversight and guidance; Thomas Carlson, Joanne Duncan, Tyrell Monter, and Matt Hennen of Pacific Northwest National Laboratory for providing invaluable assistance and support; and Pacific States Marine Fisheries Commission employees Aaron Cushing, Greg Kovalchuk and staff at John Day Dam Juvenile Smolt Facility, Dean Ballinger and staff at Bonneville Dam Juvenile Smolt Facility, Rick Martinson and Dave Marvin for providing technical support and advice. We also acknowledge the large project team of the Lower Columbia River Acoustic-Tag Investigations of Dam Passage Survival and Associated Metrics, 2010 study (employed by USACE, PNNL, PSMFC, and UW) without whose support this concurrent study could have not been accomplished. Thank you.

Animal facilities were certified by the Association for Assessment and Accreditation of Laboratory Animal Care; animals were handled in accordance with federal guidelines for the care and use of laboratory animals, and protocols were approved by the Institutional Animal Care and Use Committee, Battelle-Pacific Northwest Division. Reference to trade names does not imply endorsement by the U.S. Government. 



\section{Acronyms and Abbreviations}

\begin{tabular}{|c|c|}
\hline${ }^{\circ} \mathrm{C}$ & degree(s) Celsius (or Centigrade) \\
\hline ANOVA & analysis of variance \\
\hline AT & acoustic transmitter \\
\hline $\mathrm{BON}$ & Bonneville Dam \\
\hline df & degree of freedom \\
\hline$F$ & F-test statistic \\
\hline FCRPS & Federal Columbia River Power System \\
\hline FL & fork length \\
\hline gal & gallon(s) \\
\hline $\mathrm{hr}$ & hour(s) \\
\hline HSD & Honestly Significant Difference \\
\hline JDA & John Day Dam \\
\hline JSATS & Juvenile Salmon Acoustic Telemetry System \\
\hline $\mathrm{kg}$ & kilogram(s) \\
\hline $\mathrm{L}$ & liter(s) \\
\hline g & $\operatorname{gram}(\mathrm{s})$ \\
\hline $\mathrm{m}^{3}$ & cubic meter(s) \\
\hline $\mathrm{mg}$ & milligram(s) \\
\hline $\mathrm{mm}$ & millimeter(s) \\
\hline MS-222 & tricaine methanesulfonate \\
\hline $\mathrm{N}$ & replicates \\
\hline PIT & passive integrated transponder \\
\hline PTAGIS & PIT Tag Information System \\
\hline$p$ & p-value; probability of test statistic \\
\hline rkm & river kilometer(s) \\
\hline SD & standard deviation \\
\hline SI & surgically implanted \\
\hline SMF & Smolt Monitoring Facility \\
\hline STH & steelhead \\
\hline SYC & subyearling Chinook salmon \\
\hline WW & wet weight \\
\hline$X^{2}$ & Chi-square test statistic \\
\hline $\mathrm{YCH}$ & yearling Chinook salmon \\
\hline
\end{tabular}





\section{Contents}

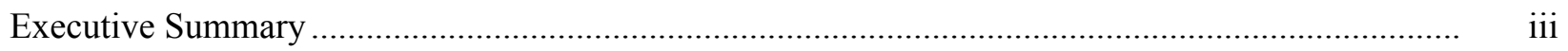

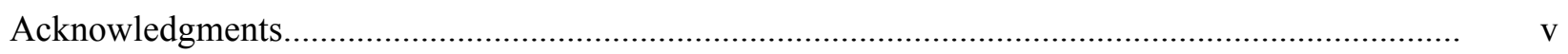

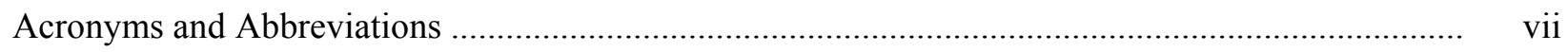

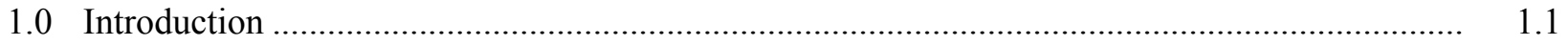

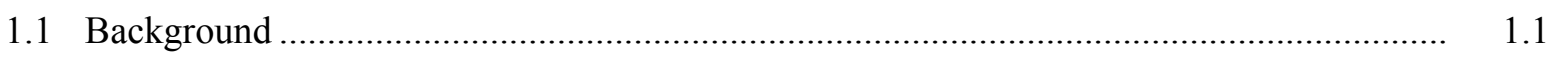

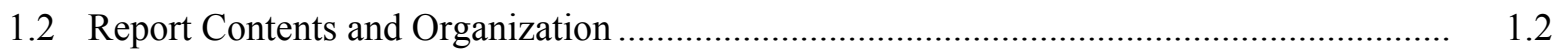

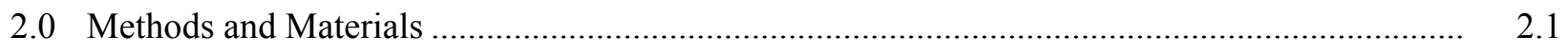

2.1 Fish Acquisition and Treatments......................................................................... 2.1

2.2 Surgical Implantation of Transmitters........................................................................ 2.2

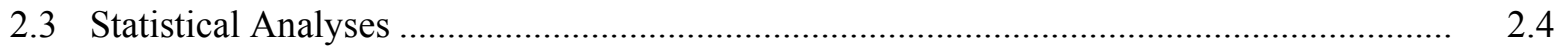

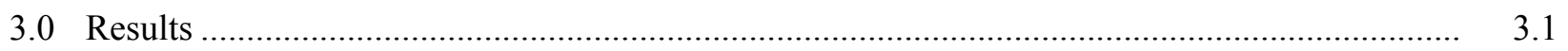

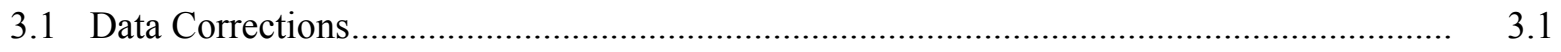

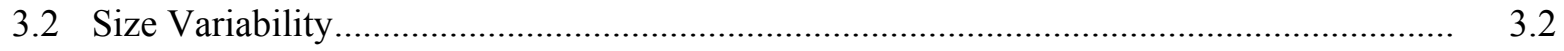

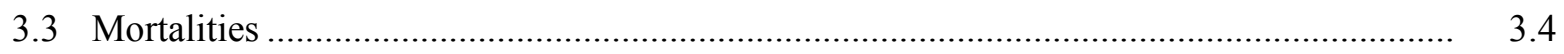

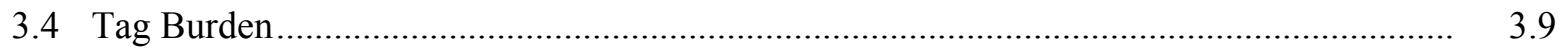

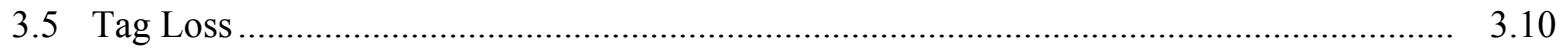

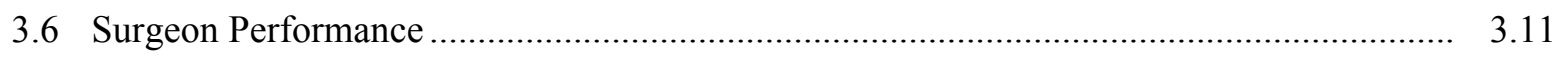

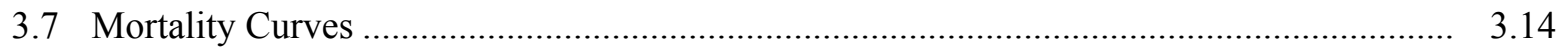

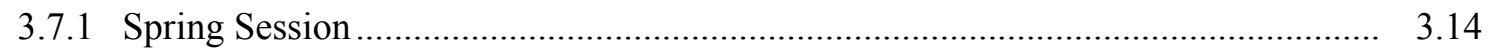

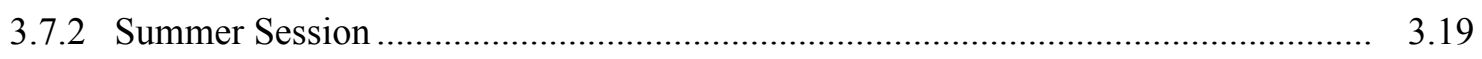

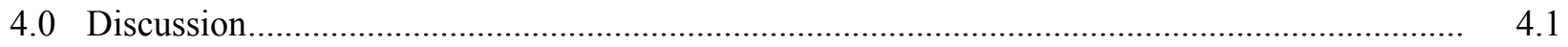

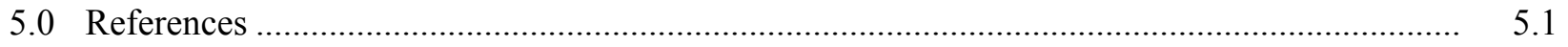




\section{Figures}

2.1 Water Temperature Collected Between May 2 and August, 2010 at the JDA SMF and the BON SMF

2.2 Dissolve Gas Percent Collected Between May 2 and August 10, 2010 at the BON SMF

3.1 Mean Percent Mortality Across Sampling Weeks for Yearling Chinook Salmon, Steelhead, and Subyearling Chinook Salmon

3.2 Week 1 YCH Fish Mortality

3.3 Week 1 STH Fish Mortality

3.4 Week 2 YCH Fish Mortality

3.5 Week 2 STH Fish Mortality

3.6 Week 3 YCH Fish Mortality

3.7 Week 3 STH Fish Mortality

3.8 Week 4 YCH Fish Mortality

3.9 Week 4 STH Fish Mortality

3.10 Week 5 YCH Fish Mortality

3.11 Week 5 YCH Fish Mortality

3.12 Week 6 SYC Fish Mortality

3.13 Week 7 SYC Fish Mortality 3.20

3.14 Week 8 SYC Fish Mortality 3.20

3.15 Week 9 SYC Fish Mortality

3.16 Week 10 SYC Fish Mortality 


\section{Tables}

2.1 Number of Fish per Species for Each Sampling Week ........................................................... 2.1

3.1 Individual Fish Removed from the Study ............................................................................

3.2 Final Number of Fish After Removals, per Species per Sampling Week................................. 3.2

3.3 Fork Length and Wet Weight Presented as Mean by Treatment Group by Sampling Week ....... 3.3

3.4 Regression Data for the Fork Length to Wet Weight Relationship .......................................... 3.3

3.5 Analysis of Variation Results for Fish Weight by Species .................................................... 3.4

3.6 Results of the Tukey-Kramer HSD Analyses of Fish Weight by Sampling Week..................... 3.4

3.7 The Number of Mortalities and the Total Number of Fish Processed per Treatment for Each

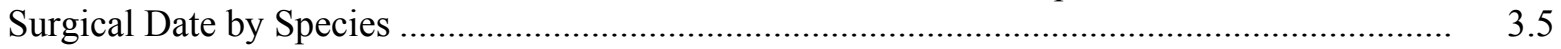

3.8 Probability of Mortality by Treatment and Fish Weight......................................................... 3.5

3.9 Probability of Mortality by Treatment and Fish Wet Weight .................................................... 3.8

3.10 Mean Days to Mortality for YCH, STH, and SYC for Each Treatment, Held 30 Days After Implantation

3.11 Tag Burden by Treatment by Species by Sampling Week ................................................... 3.9

3.12 Analysis of Variance Results for Tag Burden by Treatment by Species .................................... 3.9

3.13 Details on the AT and PIT Tags Lost During the Study ...................................................... 3.10

3.14 Acoustic and PIT-Tag Loss Percentages for the Fish that Survived for 30 Days ...................... 3.11

3.15 Number and Percentage of Mortalities and Chi-Square Results............................................. 3.12

3.16 Number of Expelled Acoustic Transmitters and PIT Tags by Surgeon.................................... 3.13

3.17 PIT and/or AT Loss Standardized by Surgeon Effort ........................................................... 3.13 



\subsection{Introduction}

In 2010, researchers at Pacific Northwest National Laboratory (PNNL) and the University of Washington (UW) conducted a compliance monitoring study for the U.S. Army Corps of Engineers, Portland District (USACE). The purpose of the study was to examine the survival model assumptions (A5 through A8) from a larger concurrent study - the Lower Columbia River Acoustic-Tag Investigations of Dam Passage Survival and Associated Metrics, 2010 (Carlson et al. 2010) at the Bonneville Juvenile Monitoring Facility - in a controlled laboratory setting using juvenile Chinook salmon (Oncorhynchus tshawytscha) and steelhead (O. mykiss). The study reported here augments PNNL and UW efforts to estimate dam passage survival at John Day Dam (JDA), The Dalles Dam (TDA), and Bonneville Dam (BON) as stipulated by the 2008 Federal Columbia River Power System (FCRPS) Biological Opinion (BiOp; NMFS 2008), and provide additional performance measures at the dam as stipulated in the Columbia Basin Fish Accords (NMFS 2008) for yearling Chinook salmon and steelhead.

To conduct this examination, we compared survival, tag burden, and tag expulsion across five spring groups of yearling Chinook salmon (YCH) and steelhead (STH) and five summer groups of subyearling Chinook salmon (SYC) implanted with Juvenile Salmon Acoustic Telemetry Systems (JSATS) microacoustic transmitter (AT) and passive integrated transponder (PIT) tags. We investigated the source of potential tag effects by comparing survival among fish implanted with both tags (AT and PIT), sham implanted fish (surgery with only a PIT tag implanted), and un-implanted (no tag implantation of any kind yet handled similar to other treatments) control fish across all tagging groups. The AT used in this and the aforementioned survival study is the smallest AT model to date, at $12 \mathrm{~mm}$ long $\times 5 \mathrm{~mm}$ wide $\times$ $4 \mathrm{~mm}$ high, and weighing $0.43 \mathrm{~g}$ in air. In spring, $\mathrm{YCH}$ and STH were collected and implanted from late April to late May. The summer collection and tagging of SYC occurred from mid-June to mid-July. The test fish were held for 30 days at the BON Smolt Monitoring Facility (SMF) to assess survival, tag burden, and tag expulsion.

\subsection{Background}

Telemetry applications for fish range from monitoring fine spatial movements and habitat preferences to monitoring large-scale migratory patterns (Skalski 1998; Scruton et al. 2007). Within rivers and basins, telemetry has proven to be an essential tool for assessing fish survival and movement patterns (Jepsen et al. 1998; Skalski 1998; Plumb et al. 2006). In the Columbia River, scientists have identified acoustic telemetry as being an essential technology for observing the behavior and estimating the survival of juvenile salmonids passing through the side channels and the main stem FCRPS (Faber et al. 2001; McComas et al. 2005; Ploskey et al. 2007; Ploskey et al. 2008; Clemens et al. 2009). Hydroelectric dams provide various routes of passage where mortality becomes pathway-specific depending on the physical properties of the technical installation (Coutant and Whitney 2000; Muir et al. 2001; Skalski et al. 2002; Weiland et al. 2009). In addition, impoundments and passage facilities may delay the outmigration of juvenile salmonids, increasing their exposure to disease and predation. Because of the direct and indirect threats to salmonids caused by impoundments, the FCRPS is being thoroughly investigated using telemetry methods and survival models.

Telemetry methodology and survival models used within the FCRPS are based on a number of assumptions that are not always tested, thus weakening the resultant data and leading to potentially

erroneous conclusions about the population of interest. A fundamental assumption of telemetry is that the 
behavior, migration, and physiological state of the fish are not affected by the transmitter presence or tagging process (Skalski et al. 2001; Deriso et al. 2007). In addition, the transmitter presence or tagging process should not affect fish growth or survival (herein referred to as "tag effects"; Jepsen et al. 2002; Zale et al. 2005). Tag effect and/or the effect of tagging responses have been a staple of the telemetry literature since 1933 (Markus 1933) and have remained a concern as newer approaches and transmitter technologies have been developed (Moore et al. 1990; Jepsen et al. 2002; Welch et al. 2007). Some studies have found no to minimal tag effects on fish (Brown et al. 1999; Chittenden et al. 2009); while others, in particular studies that use surgical implantation of transmitters, have concluded there were negative effects from transmitter presence and/or the tagging process such as reduced growth or increased mortality (Lacroix et al. 2004; Welch et al. 2007; Brown et al. 2010).

Acoustic transmitters, when used in fish survival studies, are usually surgically implanted into the coelomic cavity of the fish. Surgical implantation is a well-established method for attaching transmitters to study fish behavior and survival, although it does have disadvantages (Mulcahy 2003). Transmitter loss (or shedding) can occur through foreign body rejection processes (referred to as tag expulsion), the transmitter dropping through the incision due to poor apposition, or when external mechanical forces such as pressure are applied. In many cases, the expulsion of surgically implanted transmitters has occurred through a rupture of the incision zone (Lucas 1989; Moore et al. 1990; Petering and Johnson 1991). In other cases, the implants have exited by rupturing the abdominal body wall outside of the incision area (Marty and Summerfelt 1986; Lucas 1989) or have passed into the lumen of the intestine to be expelled by peristalsis (Martinelli1998; Baras and Westerloppe 1999). Regardless of the mechanisms or reasons for shedding, transmitter loss can affect data by indicating a mortality rate greater than the actual mortality rate. If the rate of transmitter loss and/or expulsion is documented, corrections for transmitter loss can be calculated into survival models.

Tag burden, which is the ratio of a tag (or transmitter) weight (in air) to the fish weight (in air), has been shown to be an important factor in the magnitude of the tag effect. For example, fish with low tag burdens from implanted acoustic transmitters tended to exhibit less of a tag effect with respect to tag expulsion and survival than those with higher tag burdens (Anglea et al. 2004; LaCroix et al. 2004; Brown et al. 2006; Welch et al. 2007; Chittenden et al. 2009; Hall et al. 2009; Brown et al. 2010). Previous studies using JSATS ATs reported no AT loss through 90 days for YCH experiencing mean tag burdens of 3.5 to 3.6\% (Liedtke et al. 2008; Wargo-Rub et al. 2009). Juvenile Chinook salmon implanted with JSATS ATs that resulted in tag burdens greater than $6.7 \%$, had negatively affected growth and survival rates over a 30-day study (Brown et al. 2010).

\subsection{Report Contents and Organization}

Study methods, materials, and results are described in the ensuing sections of this report. The results of this report complement the compliance monitoring study conducted by researchers at PNNL and UW for the USACE. References cited in the text are listed in the final section. 


\subsection{Methods and Materials}

This study, conducted during the two 5-week tagging periods, one in the spring and one in the summer of 2010, involved the acquisition of fish, surgical implantation of transmitters, and statistical analysis, as described below.

\subsection{Fish Acquisition and Treatments}

In spring, YCH and STH were collected and implanted from late April to late May. The summer collection and tagging of SYC occurred from mid-June to mid-July. During each week of the study, 120 fish of each species were collected at the JDA SMF (rkm 349) together with fish to be used for the concurrent dam passage survival study (Carlson et al. 2010). Fish were allowed to acclimate in 80-gal tanks with flow-through river water for 24 hours prior to the surgical process, which is further detailed in the next section. The fish were assigned to one of three treatments and then to a surgeon (Table 2.1) using a balanced block design. Treatments were as follows:

- Tagged treatment: surgically implanted with a JSATS AT and a PIT tag

- Sham treatment: surgically implanted with a PIT tag only

- Control: not surgically implanted with AT or PIT tags.

Table 2.1 lists the numbers of YCH, SYC, and STH that were collected during the spring and summer study periods ( 3 treatments and 40 fish/treatment each week). The weights of the tags were $0.43 \mathrm{~g}$ in air for the JSATS AT and $0.085 \mathrm{~g}$ in air for the PIT tag (combined weight of $0.52 \mathrm{~g}$ for the Tagged treatment).

Table 2.1. Number of Fish per Species for Each Sampling Week

\begin{tabular}{|c|c|c|c|c|c|c|c|}
\hline & Species & & & kly Colle & & & \\
\hline \multirow{3}{*}{ 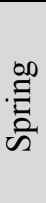 } & Date of Implantation & $\begin{array}{l}\text { Week } 1 \\
5 / 2 / 10\end{array}$ & $\begin{array}{l}\text { Week } 2 \\
5 / 9 / 10\end{array}$ & $\begin{array}{l}\text { Week } 3 \\
5 / 16 / 10\end{array}$ & $\begin{array}{l}\text { Week } 4 \\
5 / 23 / 10\end{array}$ & $\begin{array}{l}\text { Week } 5 \\
5 / 30 / 10\end{array}$ & $\begin{array}{c}\text { Total } \\
\text { Numbers }\end{array}$ \\
\hline & $\mathrm{YCH}$ & 120 & 120 & 120 & 120 & 120 & 600 \\
\hline & STH & 120 & 120 & 120 & 120 & $119^{(a)}$ & 599 \\
\hline \multirow{2}{*}{ 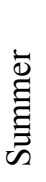 } & Date of Implantation & Week 6 & Week 7 & Week 8 & Week 9 & Week 10 & \\
\hline & SYC & 120 & 120 & 120 & 120 & 120 & 600 \\
\hline & & & & & \multicolumn{2}{|c|}{ Grand Total } & 1799 \\
\hline
\end{tabular}

(a) On May 30, 2010, 39 STH (instead of 40; Table 2.1) were assigned to the Tagged treatment due to a shortage of STH during collection the previous day. 


\subsection{Surgical Implantation of Transmitters}

Fish were anesthetized and handled similarly regardless of the treatment. A buffered anesthetic (with $80 \mathrm{mg} / \mathrm{L} \mathrm{Na}^{2} \mathrm{CO}_{3}$ ) was prepared using aerated river water and tricaine methanesulfonate (MS-222; $80 \mathrm{mg} / \mathrm{L}$ ). Prior to surgery, fish were anesthetized in buckets until loss of equilibrium was observed (Stage 4; Summerfelt and Smith 1990). Anesthetized fish were immediately weighed, measured, and both flanks were photographed. Fish were randomly assigned to one of the three treatment groups. The Tagged and Sham treatment groups underwent surgical implantation, while the Control fish bypassed the surgery stations, were placed into 5-gal, perforated recovery buckets ( 5 fish per bucket) with fresh aerated river water, and were monitored to ensure they recovered from anesthesia.

Once properly anesthetized, fish receiving surgical implants were placed on the surgery table and given a maintenance anesthetic dose (river water containing $40 \mathrm{mg} / \mathrm{L} \mathrm{MS}-222$ ) through silicone rubber tubing from a gravity-fed bucket. The surgeon controlled the dose during the procedure by mixing river water with maintenance anesthetic water. With the fish facing ventral side up, a 4- to 5-mm incision was made along the linea alba, between the pectoral fin and pelvic girdle. For Tagged fish, AT and PIT tags were inserted into the coelomic cavity through the incision. For Sham fish, only a PIT tag was inserted into the coelomic cavity. The incision was closed with two, simple interrupted sutures using a $2 \times 2 \times 2 \times 2$ wrap knot pattern with 5-0 Monocryl ${ }^{\mathrm{TM}}$ sutures.

Post-surgery, fish were placed into 5-gal perforated recovery buckets (five fish per bucket) with fresh aerated river water and monitored to ensure they recovered equilibrium. The fish density of each bucket did not exceed $15 \mathrm{~kg} / \mathrm{m}^{3}$. The buckets were placed into a larger holding tank supplied with flow-through river water. Fish were left to recover for 18 to 24 hours before being transported to the BON SMF (rkm 234; 78 driving miles, average driving time 1.5 hours). For transportation, the perforated buckets were placed into insulated transportation totes containing 200 gal of river water supplied with supplemental oxygen. Water conditions were monitored to ensure oxygen levels remained at or near saturation and water temperatures did not rise more than $1{ }^{\circ} \mathrm{C}$ from the reference temperature. Upon arrival at the BON SMF, fish were transferred (water to water) from the buckets to permanent holding tanks, where they were held for 30 days in 100-gal circular tanks or 100-gal Bonar ${ }^{\mathrm{TM}}$ totes supplied with flow-through river water, degassed to atmospheric equilibrium.

During the spring study period, an ultraviolet sterilization system (Emperor Aquatics, Pottstown, Pennsylvania) was fitted to each tank to treat the incoming river water, but this treatment was deemed ineffective and was not used for the summer session period. The drains of each tank were covered with a mesh bag to allow effluent water to flow through freely; each bag and the siphon tube was examined twice daily for any expelled JSATS AT and/or PIT tags. Fish were housed according to species and tagging date, and fed daily at $\%$ body weight (BioVita, BioOregon ${ }^{\circledR}$, Longview, Washington). Fish were monitored three times per day for signs of sickness or morbidity. Any mortalities or moribund fish were removed (moribund fish, those fish that had obvious signs of infection and were incapable of swimming without propping on the tank) were sacrificed with exposure to $250 \mathrm{mg} / \mathrm{L} \mathrm{MS}-222$, and a detailed necropsy was performed. To monitor for dropped AT and PIT tags, the siphoned effluent and mesh drain bag for each tank were examined twice daily. In addition to necropsy notes, daily notes included found transmitters or tags, water temperature at BON and JDA, dissolved oxygen levels, signs of disease, and general health notes. Water temperatures at the JDA SMF and BON SMF increased (Figure 
2.1) and dissolved gas percent decreased (Figure 2.2) over the study; however there was little change in the dissolved oxygen content, due to the inline stripping columns.

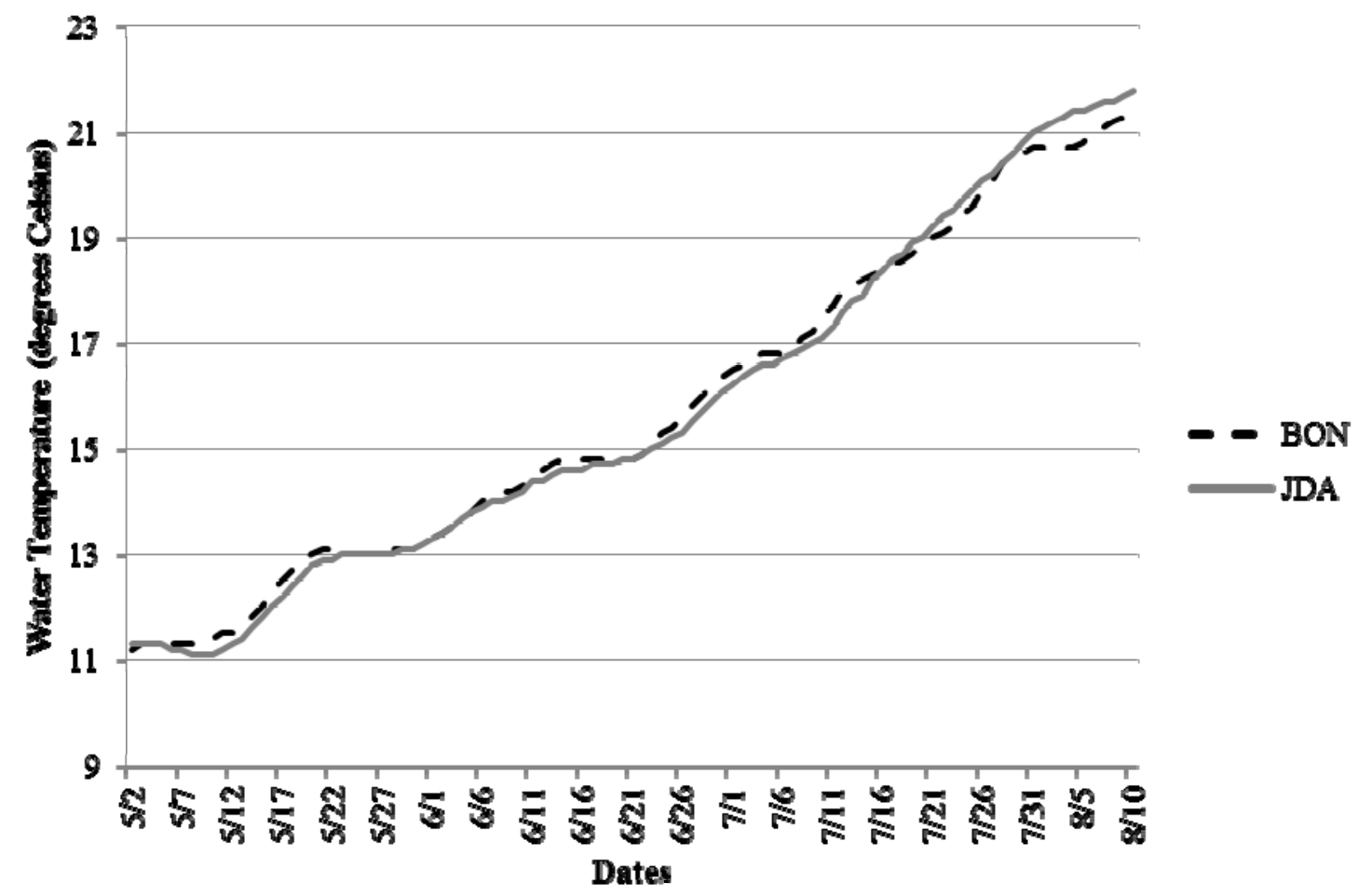

Figure 2.1. Water Temperature Collected Between May 2 and August, 2010 at the JDA SMF and the BON SMF

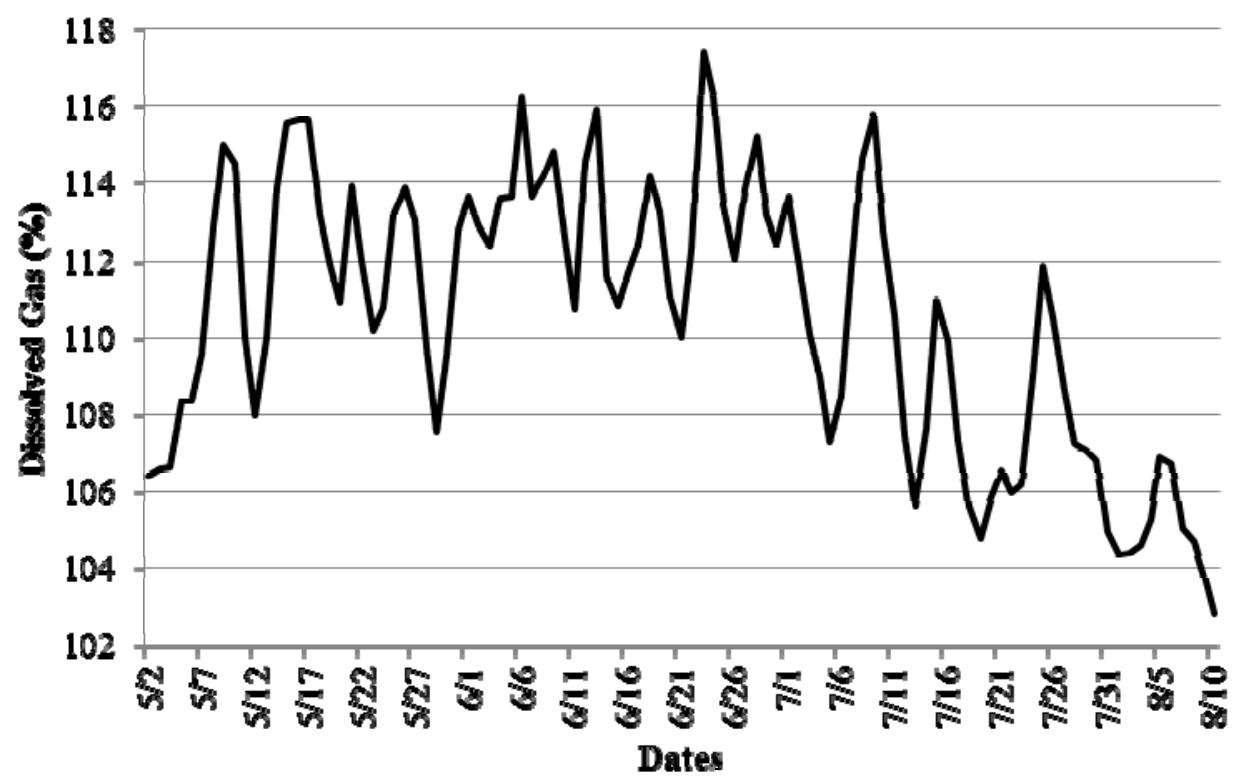

Figure 2.2. Dissolve Gas Percent Collected Between May 2 and August 10, 2010 at the BON SMF

At the conclusion of the 30-day holding period, the remaining fish were scanned for the presence of a PIT tag and the PIT-tag code was recorded (P3, Version 1.4.8, PTAGIS, Portland, Oregon). Fish were 
placed in a holding tank and released after sunset into the BON SMF outflow flume, thereby minimizing avian predation. PIT-tag codes from the released fish were logged into the PIT Tag Information System (PTAGIS) fish database program.

\subsection{Statistical Analyses}

Several tests were conducted to examine whether the fish could be pooled within a species between tanks and over weeks for multiple analyses. Fork length and wet weight were examined using Pearson's $r$ correlation. Fish size over the sampling session (i.e., 5 weeks each during spring or summer) was examined using analysis of variance (ANOVA), followed by a Tukey-Kramer Honestly Significant Difference (HSD) criterion test. Next, mortality frequencies were examined for tank effect using the nominal logistic model. Multinomial logistic models were used to investigate the interaction of sampling week and treatment on the mortality rate of each species, as well as fish size and treatment interactions on the mortality rate of each species. Tag burdens for each species and across treatments were examined using ANOVA and Tukey's HSD post hoc test. Surgeon effects were considered by using Chi-square analyses by species, using the percentage of Control mortalities as the expected frequency. ANOVA tests were used when data were normally distributed, and had acceptable statistical power; otherwise nonparametric statistics were used. All tests were significant at $p<0.05$ and conducted using JMP ${ }^{\circledR}$ (Version 8.0, Cary, North Carolina). 


\subsection{Results}

The ensuing sections describe data corrections performed during the study and results related to size variability, mortalities, tag burden, tag loss, surgeon performance, and associated mortality curves for both the spring and summer sessions.

\subsection{Data Corrections}

Several events occurred throughout the study that made it necessary to remove 28 fish from the analysis (Table 3.1). Fish were excluded from the final analysis if 1) fish were found outside of the tank for an undetermined period of time (jumped from tank; $\mathrm{N}=14$ ); 2) fish could not be reassigned at the BON SMF (e.g., deteriorated condition, non-functioning PIT tags; $\mathrm{N}=7$ ); or 3 ) fish died, were moribund, or were injured when they arrived at the BON SMF $(N=7)$. Seven of the 10 sampling periods were affected by the removal of these fish for one of the three reasons. Two weeks into the study, the elastic restraining the tank netting was discovered to be inadequate, enabling fish to jump out of the tanks. All tank cover netting was secured using new bungee cords and tension straps, thereby eliminating fish loss due to jumping. The adjusted number of fish for each holding group ranged from 111 to 120 individuals after removal of the questionable fish (Table 3.2).

Table 3.1. Individual Fish Removed from the Study

\begin{tabular}{cccccc}
\hline Surgical Date & Species & Treatment & PIT Code (Last 6) & Surgeon & Reason for Exclusion \\
\hline $05 / 02 / 2010$ & YCH & Sham & 6 D9756 & F & Jumped from tank \\
$05 / 02 / 2010$ & YCH & Tagged & $448 \mathrm{DFF}$ & $\mathrm{F}$ & Jumped from tank \\
$05 / 02 / 2010$ & STH & Tagged & $6 \mathrm{D} 2365$ & B & Jumped from tank \\
$05 / 09 / 2010$ & STH & Sham & 6 CF9A3 & A & Jumped from tank \\
$05 / 09 / 2010$ & STH & Sham & 6 D5FE1 & C & Jumped from tank \\
$05 / 09 / 2010$ & STH & Sham & 6 D989F & C & Jumped from tank \\
$05 / 09 / 2010$ & STH & Sham & 6D68EC & A & Jumped from tank \\
$05 / 09 / 2010$ & STH & Sham & 6D5F9B & E & Jumped from tank \\
$05 / 09 / 2010$ & YCH & Tagged & 6D6D00 & A & Jumped from tank \\
$05 / 09 / 2010$ & YCH & Tagged & 6D8FD4 & A & Jumped from tank \\
$05 / 09 / 2010$ & STH & Tagged & 6CF385 & A & Jumped from tank \\
$05 / 09 / 2010$ & STH & Tagged & 6E4A85 & E & Jumped from tank \\
$05 / 09 / 2010$ & STH & Tagged & 6D9252 & E & Jumped from tank \\
$05 / 09 / 2010$ & STH & Tagged & 6D9252 & A & Jumped from tank \\
$05 / 09 / 2010$ & STH & Tagged & 428DD4 & C & Could not reconcile \\
$05 / 16 / 2010$ & YCH & Sham & 504E16 & G & Could not reconcile \\
$05 / 16 / 2010$ & YCH & Tagged & 509FAA & F & Could not reconcile \\
$05 / 16 / 2010$ & YCH & Tagged & 506C25 & B & Could not reconcile \\
$05 / 16 / 2010$ & STH & Tagged & 50BEE7 & F & Could not reconcile \\
$05 / 23 / 2010$ & STH & Tagged & 50A129 & C & Could not reconcile
\end{tabular}


Table 3.1. (contd)

\begin{tabular}{|c|c|c|c|c|c|c|}
\hline & Surgical Date & Species & Treatment & PIT Code (Last 6) & Surgeon & Reason for Exclusion \\
\hline \multirow{8}{*}{$\begin{array}{l}\dot{\vec{\Xi}} \\
\text { 音 } \\
\text {. }\end{array}$} & $06 / 12 / 2010$ & SYC & Control & -- & -- & Dead on arrival \\
\hline & $06 / 12 / 2010$ & SYC & Sham & 4E1F3E & $\mathrm{H}$ & Dead on arrival \\
\hline & $06 / 12 / 2010$ & SYC & Tagged & $50 \mathrm{~F} 026$ & $\mathrm{H}$ & Moribund on arrival \\
\hline & $06 / 26 / 2010$ & SYC & Sham & $4 \mathrm{E} 14 \mathrm{C} 5$ & $\mathrm{C}$ & Could not reconcile \\
\hline & $07 / 10 / 2010$ & SYC & Control & -- & -- & Dead on arrival \\
\hline & $07 / 10 / 2010$ & SYC & Control & -- & -- & Dead on arrival \\
\hline & $07 / 10 / 2010$ & SYC & Control & -- & -- & Dead on arrival \\
\hline & $07 / 10 / 2010$ & SYC & Control & -- & -- & Dead on arrival \\
\hline
\end{tabular}

Table 3.2. Final Number of Fish After Removals, per Species per Sampling Week

\begin{tabular}{|c|c|c|c|c|c|c|c|}
\hline & Surgical Date & Species & Control & Sham & Tagged & Total Handled & $\begin{array}{l}\text { Total Surgically } \\
\text { Implanted }\end{array}$ \\
\hline \multirow{10}{*}{$\begin{array}{l}\stackrel{\infty}{\vec{\Xi}} \\
\text { के }\end{array}$} & \multirow{2}{*}{$05 / 02 / 2010$} & $\mathrm{YCH}$ & 40 & 39 & 39 & 118 & 78 \\
\hline & & STH & 40 & 40 & 39 & 119 & 79 \\
\hline & \multirow{2}{*}{ 05/09/2010 } & $\mathrm{YCH}$ & 40 & 40 & 37 & 117 & 77 \\
\hline & & STH & 40 & 35 & 36 & 111 & 71 \\
\hline & \multirow{2}{*}{$05 / 16 / 2010$} & $\mathrm{YCH}$ & 40 & 39 & 38 & 117 & 77 \\
\hline & & STH & 40 & 40 & 39 & 119 & 79 \\
\hline & \multirow{2}{*}{$05 / 23 / 2010$} & $\mathrm{YCH}$ & 40 & 40 & 40 & 120 & 80 \\
\hline & & STH & 40 & 40 & 39 & 119 & 79 \\
\hline & \multirow{2}{*}{$05 / 30 / 2010$} & $\mathrm{YCH}$ & 40 & 40 & 40 & 120 & 80 \\
\hline & & STH & 40 & 40 & 39 & 119 & 79 \\
\hline \multirow{5}{*}{ 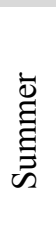 } & $06 / 12 / 2010$ & SYC & 39 & 39 & 40 & 118 & 79 \\
\hline & $06 / 19 / 2010$ & SYC & 40 & 40 & 40 & 120 & 80 \\
\hline & $06 / 26 / 2010$ & SYC & 40 & 39 & 40 & 119 & 79 \\
\hline & $07 / 03 / 2010$ & SYC & 40 & 40 & 40 & 120 & 80 \\
\hline & $07 / 10 / 2010$ & SYC & 36 & 40 & 40 & 116 & 80 \\
\hline
\end{tabular}

\subsection{Size Variability}

At the time of tagging, fork lengths (FLs) and wet weights (WWs) ranged, respectively, from 110 to $214 \mathrm{~mm}$ and 12.9 to $102.1 \mathrm{~g}$ for $\mathrm{YCH}$; from 132 to $260 \mathrm{~mm}$ and 17.0 to $144.5 \mathrm{~g}$ for STH; and from 95 to $138 \mathrm{~mm}$ and 7.6 to $27.7 \mathrm{~g}$ for SYC. There were no significant differences between tank assignment and fish size for each week by species (all $F(1,69-71)>0.01$, all $p>0.33$ ). Fork length for each species significantly predicted that species' WW (all $p<0.01$; Tables 3.3 and 3.4). As expected for juvenile outmigrating salmonids, weekly fish weight varied over the sampling season for each species (all $p<$ 0.01; Table 3.5). Using Tukey-Kramer HSD criterion, YCH from the third sampling week (05/16/2010) weighed significantly more than those from the second and third week (all $p<0.01$; Table 3.6), and YCH from the fourth sampling week $(05 / 23 / 2010)$ weighed significantly less than those from the first and the 
third sampling weeks $(05 / 02 / 2010$ and $05 / 16 / 2010)$. STH sampled during the first week $(05 / 02 / 2010)$ weighed significantly more than those from the second and third weeks (all $p<0.01 ; 05 / 09 / 2010$ and 05/16/2010; Table 3.6). Finally, SYC sampled during the fifth week $(07 / 11 / 2010)$ weighed significantly more than those from the second, third, and fourth weeks (all $p<0.01 ; 06 / 20 / 2010,06 / 27 / 2010$, and 07/04/2010; Table 3.6).

Table 3.3. Fork Length and Wet Weight Presented as Mean (SD) by Treatment Group by Sampling Week

\begin{tabular}{|c|c|c|c|c|c|}
\hline & Species & Surgery Date & Control & Sham & Tagged \\
\hline \multirow{10}{*}{$\begin{array}{l}0^{\infty} \\
\text { 竞 }\end{array}$} & \multirow{5}{*}{$\mathrm{YCH}$} & 05/02/2010 & $\begin{array}{c}165(19.7) \mathrm{mm} \\
43.1(15.9) \mathrm{g}\end{array}$ & $\begin{array}{c}161(17.7) \mathrm{mm} \\
36.9(11.9) \mathrm{g}\end{array}$ & $\begin{array}{c}165(19.4) \mathrm{mm} \\
40.8(13.9) \mathrm{g}\end{array}$ \\
\hline & & 05/09/2010 & $\begin{array}{c}149(19.0) \mathrm{mm} \\
31.4(14.3) \mathrm{g}\end{array}$ & $\begin{array}{c}152(18.1) \mathrm{mm} \\
32.3(12.9) \mathrm{g}\end{array}$ & $\begin{array}{c}153(19.2) \mathrm{mm} \\
33.9(14.4) \mathrm{g}\end{array}$ \\
\hline & & 05/16/2010 & $\begin{array}{c}169(27.0) \mathrm{mm} \\
47.9(24.2) \mathrm{g}\end{array}$ & $\begin{array}{c}173(27.0) \mathrm{mm} \\
50.9(23.6) \mathrm{g}\end{array}$ & $\begin{array}{c}158(25.0) \mathrm{mm} \\
38.0(18.8) \mathrm{g}\end{array}$ \\
\hline & & 05/23/2010 & $\begin{array}{c}146(18.2) \mathrm{mm} \\
29.5(11.6) \mathrm{g}\end{array}$ & $\begin{array}{c}145(15.6) \mathrm{mm} \\
27.4(10.4) \mathrm{g}\end{array}$ & $\begin{array}{c}147(19.4) \mathrm{mm} \\
29.5(15.3) \mathrm{g}\end{array}$ \\
\hline & & 05/30/2010 & $\begin{array}{c}144(18.1) \mathrm{mm} \\
28.7(17.0) \mathrm{g}\end{array}$ & $\begin{array}{c}147(22.0) \mathrm{mm} \\
32.0(17.3) \mathrm{g}\end{array}$ & $\begin{array}{c}154(24.1) \mathrm{mm} \\
36.4(18.9) \mathrm{g}\end{array}$ \\
\hline & \multirow{5}{*}{ STH } & $05 / 02 / 2010$ & $\begin{array}{c}221(18.7) \mathrm{mm} \\
88.2(20.4) \mathrm{g}\end{array}$ & $\begin{array}{c}222(19.5) \mathrm{mm} \\
90.3(21.0) \mathrm{g}\end{array}$ & $\begin{array}{c}206(19.6) \mathrm{mm} \\
72.1(22.0) \mathrm{g}\end{array}$ \\
\hline & & 05/09/2010 & $\begin{array}{c}209(20.4) \mathrm{mm} \\
73.5(21.8) \mathrm{g}\end{array}$ & $\begin{array}{c}215(24.3) \mathrm{mm} \\
85.4(26.5) \mathrm{g}\end{array}$ & $\begin{array}{c}217(18.5) \mathrm{mm} \\
80.3(22.0) \mathrm{g}\end{array}$ \\
\hline & & 05/16/2010 & $\begin{array}{l}201(25.9) \mathrm{mm} \\
78.1(27.9) \mathrm{g}\end{array}$ & $\begin{array}{c}205(24.7) \mathrm{mm} \\
71.0(28.2) \mathrm{g}\end{array}$ & $\begin{array}{c}209(24.4) \mathrm{mm} \\
75.2(27.5) \mathrm{g}\end{array}$ \\
\hline & & 05/23/2010 & $\begin{array}{c}206(24.6) \mathrm{mm} \\
73.5(23.5) \mathrm{g}\end{array}$ & $\begin{array}{c}211(26.1) \mathrm{mm} \\
78.2(25.1) \mathrm{g}\end{array}$ & $\begin{array}{c}211(27.4) \mathrm{mm} \\
79.2(26.8) \mathrm{g}\end{array}$ \\
\hline & & 05/30/2010 & $\begin{array}{c}226(17.7) \mathrm{mm} \\
96.0(23.7) \mathrm{g} \\
\end{array}$ & $\begin{array}{c}211(26.6) \mathrm{mm} \\
79.7(29.4) \mathrm{g} \\
\end{array}$ & $\begin{array}{c}215(25.2) \mathrm{mm} \\
81.3(27.8) \mathrm{g} \\
\end{array}$ \\
\hline \multirow{5}{*}{$\begin{array}{l}\dot{\bar{\Xi}} \\
\dot{\Xi} \\
\text { है }\end{array}$} & \multirow{5}{*}{ SYC } & 06/13/2010 & $\begin{array}{c}112(7.35) \mathrm{mm} \\
13.2(2.6) \mathrm{g}\end{array}$ & $\begin{array}{c}115(7.3) \mathrm{mm} \\
14.1(2.8) \mathrm{g}\end{array}$ & $\begin{array}{c}111(6.6) \mathrm{mm} \\
12.7(2.7) \mathrm{g}\end{array}$ \\
\hline & & 06/20/2010 & $\begin{array}{c}112(7.3) \mathrm{mm} \\
12.0(1.8) \mathrm{g}\end{array}$ & $\begin{array}{c}111(6.2) \mathrm{mm} \\
12.6(2.4) \mathrm{g}\end{array}$ & $\begin{array}{c}110(6.7) \mathrm{mm} \\
12.5(2.5) \mathrm{g}\end{array}$ \\
\hline & & 06/27/2010 & $\begin{array}{l}109(7.4) \mathrm{mm} \\
12.4(3.0) \mathrm{g}\end{array}$ & $\begin{array}{c}110(5.6) \mathrm{mm} \\
12.4(2.0) \mathrm{g}\end{array}$ & $\begin{array}{c}110(4.5) \mathrm{mm} \\
12.5(1.7) \mathrm{g}\end{array}$ \\
\hline & & 07/04/2010 & $\begin{array}{l}110(5.3) \mathrm{mm} \\
12.5(2.3) \mathrm{g}\end{array}$ & $\begin{array}{l}109(5.9) \mathrm{mm} \\
12.1(2.0) \mathrm{g}\end{array}$ & $\begin{array}{c}109(5.9) \mathrm{mm} \\
12.4(2.1) \mathrm{g}\end{array}$ \\
\hline & & $07 / 11 / 2010$ & $\begin{array}{c}114(8.6) \mathrm{mm} \\
14.9(3.5) \mathrm{g}\end{array}$ & $\begin{array}{c}113(9.9) \mathrm{mm} \\
14.5(4.4) \mathrm{g}\end{array}$ & $\begin{array}{c}111(6.8) \mathrm{mm} \\
13.6(2.6) \mathrm{g} \\
\end{array}$ \\
\hline
\end{tabular}

Table 3.4. Regression Data for the Fork Length ( $\mathrm{mm}$ ) to Wet Weight (g) Relationship

\begin{tabular}{ccccccc}
\hline Species & Intercept & Slope & $r^{2}$ & $\mathrm{~N}$ & $F$ & $p$ \\
\hline YCH & 110.51 & 1.26 & 0.93 & 392 & 5108.08 & $<0.0001$ \\
STH & 140.77 & 0.90 & 0.93 & 387 & 5220.62 & $<0.0001$ \\
SYC & 79.29 & 2.44 & 0.90 & 395 & 3417.36 & $<0.0001$ \\
\hline
\end{tabular}


Table 3.5. Analysis of Variation Results for Fish Weight by Species

\begin{tabular}{ccccccc}
\hline Species & Mean & SD & N & df & $F$ & $p$ \\
\hline YCH & 35.73 & 17.19 & 392 & 4,387 & 10.88 & $<0.0001$ \\
STH & 79.35 & 26.12 & 387 & 4,382 & 3.64 & 0.0064 \\
SYC & 12.87 & 2.56 & 395 & 4,390 & 5.40 & 0.0003 \\
\hline
\end{tabular}

Table 3.6. Results of the Tukey-Kramer HSD Analyses of Fish Weight by Sampling Week. For each species, weeks that are not connected by the same letter are significantly different.

\begin{tabular}{|c|c|c|c|c|c|c|}
\hline & Species & Week & Mean & SD & $\mathrm{N}$ & Significance \\
\hline \multirow{10}{*}{ 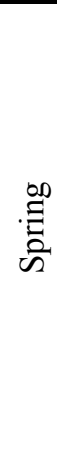 } & \multirow{5}{*}{$\mathrm{YCH}$} & $05 / 02 / 2010$ & 38.8 & 13.0 & 78 & A, B \\
\hline & & $05 / 09 / 2010$ & 33.1 & 13.6 & 77 & $\mathrm{~B}, \mathrm{C}$ \\
\hline & & $05 / 16 / 2010$ & 44.5 & 22.2 & 77 & A \\
\hline & & $05 / 23 / 2010$ & 28.4 & 13.0 & 80 & $\mathrm{C}$ \\
\hline & & $05 / 30 / 2010$ & 34.2 & 18.2 & 80 & $\mathrm{~B}, \mathrm{C}$ \\
\hline & \multirow{5}{*}{ STH } & $05 / 02 / 2010$ & 87.9 & 23.8 & 79 & A \\
\hline & & $05 / 09 / 2010$ & 76.3 & 22.2 & 71 & B \\
\hline & & $05 / 16 / 2010$ & 73.1 & 27.7 & 79 & B \\
\hline & & $05 / 23 / 2010$ & 78.7 & 25.8 & 79 & A, B \\
\hline & & $05 / 30 / 2010$ & 80.5 & 28.4 & 79 & $\mathrm{~A}, \mathrm{~B}$ \\
\hline \multirow{5}{*}{$\begin{array}{l}\overline{\bar{\Xi}} \\
\text { 音 } \\
\text { ڤn }\end{array}$} & \multirow{5}{*}{ SYC } & $06 / 13 / 2010$ & 13.3 & 2.7 & 78 & A, B \\
\hline & & $06 / 20 / 2010$ & 12.6 & 2.4 & 80 & B \\
\hline & & $06 / 27 / 2010$ & 12.5 & 1.9 & 79 & B \\
\hline & & $07 / 04 / 2010$ & 12.3 & 2.1 & 80 & B \\
\hline & & $07 / 11 / 2010$ & 13.8 & 3.3 & 78 & A \\
\hline
\end{tabular}

\subsection{Mortalities}

The project suffered high mortalities (Table 3.7), regardless of attempts made to condition the holding water, disinfect gear and tanks, and administer medicated feed. Mortality ranged from 45 to $72 \%$ for $\mathrm{YCH}, 55$ to $83 \%$ for STH, and 56 to $84 \%$ for SYC, depending on treatment. Fungal infections were noted on $35 \%$ of all study fish (33\% YCH, $40 \% \mathrm{STH}$, and $30 \% \mathrm{SYC})$. Ulcerations near the abdominal area appear to be due to sutures tearing or infections that resulted in loss of abdominal tissue $(0 \% \mathrm{YCH}$, $5 \% \mathrm{STH}$, and $9 \% \mathrm{SYC}$ ). Descaling was observed on $49 \%$ of all fish necropsied, with $15 \%$ showing greater than $20 \%$ descaling. With the exception the YCH week 5 tagging group $\left(X^{2}=4.15, p=0.042\right)$, tank assignments for each weekly treatment (e.g., the number of fish in each tank per treatment) were balanced. There were no significant differences in mortality rates for the other tanks by week or species. Regardless of the presence or absence of the week $5 \mathrm{YCH}$ group in the multinomial logistic model, WW and treatment affected mortality rate $\left(X^{2}(3, \mathrm{~N}=387) 16.31, p<0.01\right.$; Table 3.8). For example, the week $3 \mathrm{YCH}$ Sham treatment group $(\mathrm{WW}=50.9 \pm 23.6 \mathrm{~g}$ ) had a greater mortality rate compared to the smaller week 4 YCH Sham treatment group (WW $=27.4 \pm 10.4 \mathrm{~g}$ ). A similar result was seen for SYC where fish weight and tag treatment affected mortality rate $\left(X^{2}(3, N=390) 30.70, p<0.01\right.$; Table 3.8). The week 5 SYC Control group $(\mathrm{WW}=14.9 \pm 3.5 \mathrm{~g})$ had a greater mortality rate than the smaller fish composing the week $2 \mathrm{SYC}$ Control group $(\mathrm{WW}=12.0 \pm 1.8 \mathrm{~g})$. 
Table 3.7. The Number of Mortalities and the Total Number of Fish Processed (in parentheses) per Treatment for Each Surgical Date by Species

\begin{tabular}{|c|c|c|c|c|c|c|}
\hline & Species & Surgical Date & Control & Sham & Tagged & Total Mortality \\
\hline \multirow{10}{*}{ 告 } & \multirow{5}{*}{$\mathrm{YCH}$} & $05 / 02 / 2010$ & $21(40)$ & $16(39)$ & $17(39)$ & $54(118)$ \\
\hline & & 05/09/2010 & $12(40)$ & $30(30)$ & $27(37)$ & 69 (117) \\
\hline & & $05 / 16 / 2010$ & $18(40)$ & $27(38)$ & $21(38)$ & 66 (117) \\
\hline & & $05 / 23 / 2010$ & $22(40)$ & $17(40)$ & $24(40)$ & $63(120)$ \\
\hline & & $05 / 30 / 2010$ & $27(40)$ & $28(40)$ & $31(40)$ & $86(120)$ \\
\hline & \multirow{5}{*}{ STH } & $05 / 02 / 2010$ & $19(40)$ & $27(30)$ & $33(39)$ & 79 (119) \\
\hline & & 05/09/2010 & $30(40)$ & $29(35)$ & $26(36)$ & 85 (111) \\
\hline & & $05 / 16 / 2010$ & $33(40)$ & $32(39)$ & $31(39)$ & $96(119)$ \\
\hline & & $05 / 23 / 2010$ & $22(40)$ & $30(40)$ & $26(39)$ & 78 (119) \\
\hline & & 05/30/2010 & $33(40)$ & $30(40)$ & $36(39)$ & 99 (119) \\
\hline \multirow{5}{*}{ 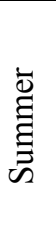 } & \multirow{5}{*}{ SYC } & $06 / 13 / 2010$ & $25(39)$ & $24(39)$ & $31(40)$ & $80(118)$ \\
\hline & & $06 / 20 / 2010$ & $15(40)$ & $24(40)$ & $28(40)$ & $67(120)$ \\
\hline & & $06 / 27 / 2010$ & $21(40)$ & $23(39)$ & $30(40)$ & 74 (119) \\
\hline & & 07/04/2010 & $29(40)$ & $25(40)$ & $29(40)$ & $83(120)$ \\
\hline & & $07 / 11 / 2010$ & $36(36)$ & $28(40)$ & $34(40)$ & $98(116)$ \\
\hline
\end{tabular}

Table 3.8. Probability of Mortality by Treatment and Fish Weight. Chi-square results for the relationships between fish wet weight and treatment and their interaction effects on mortality.

\begin{tabular}{|c|c|c|c|c|c|c|c|c|}
\hline & Species & Surgical Date & $X^{2}$ & $p$ & Mortality \% & Main df & Main $X^{2}$ & Main $p$ \\
\hline \multirow{12}{*}{ 告 } & \multirow{6}{*}{$\mathrm{YCH}$} & FL (mm) & 15.46 & $<0.00$ & & \multirow[t]{6}{*}{3} & \multirow[t]{6}{*}{16.39} & \multirow[t]{6}{*}{$<0.00$} \\
\hline & & Treatment & 0.25 & 0.62 & & & & \\
\hline & & Control & & & 50.0 & & & \\
\hline & & Sham & & & 59.6 & & & \\
\hline & & Tagged & & & 61.9 & & & \\
\hline & & FL $*$ Treatment & 0.22 & 0.64 & & & & \\
\hline & \multirow{6}{*}{ STH } & FL (mm) & 0.87 & 0.35 & & \multirow[t]{6}{*}{3} & \multirow[t]{6}{*}{2.63} & \multirow[t]{6}{*}{0.45} \\
\hline & & Treatment & 6.182 & 0.41 & & & & \\
\hline & & Control & & & 68.5 & & & \\
\hline & & Sham & & & 75.9 & & & \\
\hline & & Tagged & & & 79.2 & & & \\
\hline & & FL $*$ Treatment & 1.02 & 0.31 & & & & \\
\hline \multirow{6}{*}{$\begin{array}{l}\bar{\Phi} \\
\bar{\Xi} \\
\bar{\Xi}\end{array}$} & \multirow{6}{*}{ SYC } & FL (mm) & 17.87 & $<0.00$ & & \multirow[t]{6}{*}{3} & \multirow[t]{6}{*}{30.704} & \multirow[t]{6}{*}{$<0.00$} \\
\hline & & Treatment & 8.71 & $<0.00$ & & & & \\
\hline & & Control & & & 64.6 & & & \\
\hline & & Sham & & & 62.6 & & & \\
\hline & & Tagged & & & 76.0 & & & \\
\hline & & $\mathrm{FL} *$ Treatment & 8.67 & $<0.00$ & & & & \\
\hline
\end{tabular}


For $\mathrm{YCH}$, the mean percent mortality by treatment across sampling weeks was $50 \%$ for the Control, $60 \%$ for the Sham, and $62 \%$ for the Tagged groups. This order changed for SYC with $65 \%$ mortality for the Control, $63 \%$ for the Sham, and $76 \%$ for the Tagged groups. Although the ranking changed between $\mathrm{YCH}$ and $\mathrm{SYC}$, the main effects (treatment, sampling week) and interactions ( $\mathrm{df}=14 ; p \leq 0.01)$ significantly affected mortality rates $(\mathrm{df}=2,4$; all $p<0.03$; Table 3.9$)$. YCH mortality rates were greatest in the Control group for the first week, followed by the Tagged and then Sham groups. During the second and third weeks, Sham groups had the greatest mortality, and during the fourth and fifth week, the greatest mortality was in the Tagged groups. Conversely, the SYC mortality rate was greatest in the Tagged treatment group for the first of four of the five week long periods. The Control treatment in the fifth week had the greatest mortality, followed by Tagged and then Sham groups (Figure 3.1).

For STH, the mean percent mortality by treatment across sampling weeks was $71 \%$ for the Control, $76 \%$ for the Sham, and $79 \%$ for the Tagged groups. For STH, the interaction was significant $(\mathrm{df}=14$, $p<0.01$ ), although the main effects were mixed (treatment $\mathrm{df}=2, p=0.07$; sampling week $\mathrm{df}=4$, $p<0.01$; Table 3.9).

Mortality across the holding period for each of the 10 holding groups broken down by species and mean days to mortality are shown in Table 3.10, and surgeon and treatment data can be seen in Figures 3.2 through 3.16 in Section 3.7. 

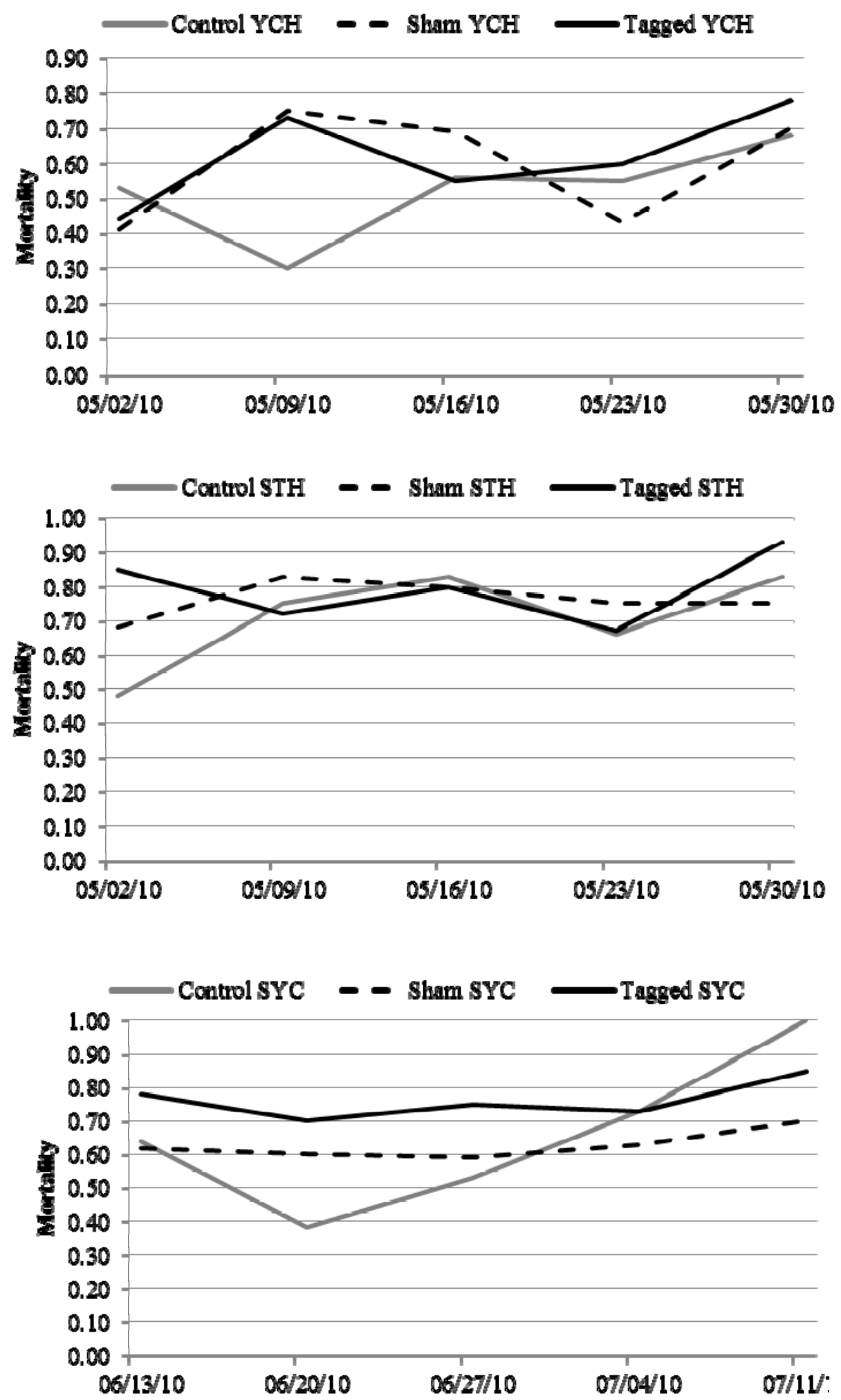

Figure 3.1. Mean Percent Mortality Across Sampling Weeks for Yearling Chinook Salmon, Steelhead, and Subyearling Chinook Salmon 
Table 3.9. Probability of Mortality by Treatment and Fish Wet Weight. The results are presented in the first row for each species and are related to the whole model test not specific to the week row. The "*” indicates the treatment with the greatest mortality for the corresponding surgical date.

\begin{tabular}{|c|c|c|c|c|c|c|c|c|c|}
\hline & Species & Surgical Date & Total & Control & Sham & Tagged & $\mathrm{df}$ & $X^{2}$ & $p$ \\
\hline \multirow{10}{*}{ 榓 } & \multirow{5}{*}{$\mathrm{YCH}$} & $05 / 02 / 2010$ & 0.46 & $0.53 *$ & 0.41 & 0.44 & \multirow[t]{5}{*}{14} & \multirow[t]{5}{*}{49.25} & \multirow[t]{5}{*}{0.0001} \\
\hline & & 05/09/2010 & 0.59 & 0.30 & $0.75^{*}$ & 0.73 & & & \\
\hline & & $05 / 16 / 2010$ & 0.45 & 0.56 & $0.69 *$ & 0.55 & & & \\
\hline & & $05 / 23 / 2010$ & 0.53 & 0.55 & 0.43 & $0.60 *$ & & & \\
\hline & & $05 / 30 / 2010$ & 0.72 & 0.68 & 0.70 & $0.78 *$ & & & \\
\hline & \multirow{5}{*}{ STH } & $05 / 02 / 2010$ & 0.66 & 0.48 & 0.68 & $0.85^{*}$ & \multirow[t]{5}{*}{14} & \multirow[t]{5}{*}{38.71} & \multirow[t]{5}{*}{0.0004} \\
\hline & & 05/09/2010 & 0.77 & 0.75 & $0.83^{*}$ & 0.72 & & & \\
\hline & & $05 / 16 / 2010$ & 0.81 & $0.83 *$ & 0.80 & 0.80 & & & \\
\hline & & $05 / 23 / 2010$ & 0.55 & 0.66 & $0.75^{*}$ & 0.67 & & & \\
\hline & & $05 / 30 / 2010$ & $0.83^{*}$ & 0.83 & 0.75 & $0.93 *$ & & & \\
\hline \multirow{5}{*}{$\begin{array}{c}\bar{\Phi} \\
\stackrel{\Xi}{\Xi} \\
\bar{\Xi}\end{array}$} & \multirow{5}{*}{ SYC } & $06 / 13 / 2010$ & 0.68 & 0.64 & 0.62 & $0.78 *$ & \multirow[t]{5}{*}{14} & \multirow[t]{5}{*}{61.28} & \multirow[t]{5}{*}{$<0.0001$} \\
\hline & & $06 / 20 / 2010$ & 0.56 & 0.38 & 0.60 & $0.70 *$ & & & \\
\hline & & $06 / 27 / 2010$ & 0.62 & 0.53 & 0.59 & $0.75^{*}$ & & & \\
\hline & & $07 / 04 / 2010$ & 0.69 & $0.73^{*}$ & 0.63 & $0.73^{*}$ & & & \\
\hline & & $07 / 11 / 2010$ & 0.84 & $1.00^{*}$ & 0.70 & 0.85 & & & \\
\hline
\end{tabular}

Table 3.10.Mean Days to Mortality ( \pm SD [range]) for YCH, STH, and SYC for Each Treatment, Held 30 Days After Implantation

\begin{tabular}{|c|c|c|c|c|c|}
\hline & Species & Surgical Date & Control & Sham & Tagged \\
\hline \multirow{10}{*}{$\begin{array}{l}\text { Do } \\
\text { की } \\
\text { की }\end{array}$} & \multirow{5}{*}{$\mathrm{YCH}$} & $05 / 02 / 2010$ & $20.7 \pm 6.7$ & $23.5 \pm 7.1$ & $22.2 \pm 6.8$ \\
\hline & & 05/09/2010 & $26.0 \pm 4.1$ & $20.0 \pm 5.2$ & $19.9 \pm 6.9$ \\
\hline & & 05/16/2010 & $15.4 \pm 8.6$ & $14.0 \pm 9.6$ & $17.9 \pm 8.9$ \\
\hline & & $05 / 23 / 2010$ & $19.3 \pm 7.6$ & $14.4 \pm 7.6$ & $14.0 \pm 7.8$ \\
\hline & & 05/30/2010 & $19.7 \pm 8.3$ & $21.6 \pm 4.8$ & $19.7 \pm 7.6$ \\
\hline & \multirow{5}{*}{ STH } & $05 / 02 / 2010$ & $12.7 \pm 3.5$ & $11.3 \pm 2.3$ & $11.8 \pm 3.1$ \\
\hline & & 05/09/2010 & $14.0 \pm 4.7$ & $12.9 \pm 4.8$ & $12.5 \pm 3.1$ \\
\hline & & 05/16/2010 & $9.5 \pm 2.9$ & $10.0 \pm 3.2$ & $9.1 \pm 3.0$ \\
\hline & & 05/23/2010 & $10.3 \pm 3.1$ & $9.1 \pm 3.4$ & $10.4 \pm 3.7$ \\
\hline & & 05/30/2010 & $10.9 \pm 2.9$ & $10.5 \pm 3.3$ & $10.7 \pm 4.9$ \\
\hline \multirow{5}{*}{ 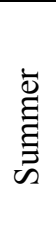 } & \multirow{5}{*}{ SYC } & $06 / 13 / 2010$ & $24.9 \pm 3.3$ & $20.7 \pm 6.1$ & $19.5 \pm 7.6$ \\
\hline & & 06/20/2010 & $22.8 \pm 2.5$ & $18.6 \pm 5.7$ & $19.5 \pm 4.7$ \\
\hline & & 06/27/2010 & $18.9 \pm 5.3$ & $14.3 \pm 2.4$ & $16.6 \pm 5.2$ \\
\hline & & 07/04/2010 & $19.8 \pm 6.4$ & $10.7 \pm 4.2$ & $10.8 \pm 3.3$ \\
\hline & & 07/11/2010 & $9.52 \pm 4.2$ & $7.3 \pm 5.0$ & $7.5 \pm 5.0$ \\
\hline
\end{tabular}




\subsection{Tag Burden}

Fish WW significantly varied across tagging weeks and thus caused a significant difference in tag burdens across sampling weeks (Table 3.11). Using ANOVA and Tukey's HSD post hoc test, the tag burden for the Sham treatment in $\mathrm{YCH}$ was significantly greater during the fourth week of tagging $(\overline{\mathrm{x}}=0.34$; Table $3.11,3.12)$ than during the first and third weeks $(\overline{\mathrm{x}}=0.26$ and 0.21 , respectively; $p<0.01)$. The tag burden for the Sham treatment in STH during the first week of sampling $(\overline{\mathrm{x}}=0.11)$ was significantly lower than during the second and fifth weeks (all $\overline{\mathrm{x}}=0.14 ; p<0.05$ ). The tag burden for Sham treatment in SYC was significantly greater during the third week of tagging $(\overline{\mathrm{x}}=0.72)$ than during the first, fourth, and fifth weeks of sampling (all $\overline{\mathrm{x}}=0.68 ; p<0.02$ ).

Comparing treatment groups using ANOVA, the YCH Tagged treatment group was the only group where tag burden significantly varied over the tagging period $(p<0.01$; Table $3.11,3.12)$. More specifically, the first week of tagging had a significantly lower tag burden $(\bar{x}=1.34)$ than the fourth week of tagging $(\overline{\mathrm{x}}=1.95, p<0.01)$. For STH and SYC, there were no significant differences among weeks (all $p>0.23$; Table 3.11, 3.12).

Table 3.11. Tag Burden by Treatment by Species by Sampling Week

\begin{tabular}{|c|c|c|c|c|}
\hline & Species & Surgical Date & Sham & Tagged \\
\hline \multirow{10}{*}{ 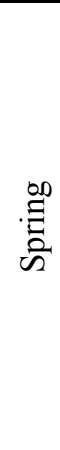 } & \multirow{5}{*}{$\mathrm{YCH}$} & $05 / 02 / 2010$ & $0.26 \pm 0.09$ & $1.34 \pm 6.8$ \\
\hline & & 05/09/2010 & $0.32 \pm 0.11$ & $1.67 \pm 6.9$ \\
\hline & & 05/16/2010 & $0.21 \pm 0.13$ & $1.41 \pm 8.9$ \\
\hline & & $05 / 23 / 2010$ & $0.34 \pm 0.12$ & $1.95 \pm 7.8$ \\
\hline & & $05 / 30 / 2010$ & $0.27 \pm 0.12$ & $1.41 \pm 7.6$ \\
\hline & \multirow{5}{*}{ STH } & $05 / 02 / 2010$ & $0.11 \pm 0.04$ & $0.70 \pm 0.31$ \\
\hline & & 05/09/2010 & $0.14 \pm 0.04$ & $0.70 \pm 0.23$ \\
\hline & & 05/16/2010 & $0.13 \pm 0.04$ & $0.80 \pm 0.28$ \\
\hline & & $05 / 23 / 2010$ & $0.13 \pm 0.05$ & $0.71 \pm 0.45$ \\
\hline & & $05 / 30 / 2010$ & $0.14 \pm 0.04$ & $0.63 \pm 0.28$ \\
\hline \multirow{5}{*}{$\begin{array}{l}\bar{\Xi} \\
\text { 音 } \\
\text { ڤn }\end{array}$} & \multirow{5}{*}{ SYC } & $06 / 13 / 2010$ & $0.68 \pm 0.12$ & $3.98 \pm 0.82$ \\
\hline & & $06 / 20 / 2010$ & $0.75 \pm 0.13$ & $3.72 \pm 0.84$ \\
\hline & & $06 / 27 / 2010$ & $0.76 \pm 0.12$ & $4.21 \pm 0.60$ \\
\hline & & $07 / 04 / 2010$ & $0.68 \pm 0.12$ & $3.85 \pm 0.71$ \\
\hline & & $07 / 11 / 2010$ & $0.68 \pm 0.16$ & $3.93 \pm 0.80$ \\
\hline
\end{tabular}

Table 3.12. Analysis of Variance Results for Tag Burden by Treatment by Species

\begin{tabular}{cccccccc}
\hline Species & Treatment & Mean & SD & N & df & $F$ & $p$ \\
\hline \multirow{2}{*}{ YCH } & Sham & 0.290 & 0.121 & 198 & 4,193 & 8.4357 & $<0.0001$ \\
& Tagged & 1.742 & 0.728 & 194 & 4,189 & 3.5836 & 0.0077 \\
\multirow{2}{*}{ STH } & Sham & 0.127 & 0.045 & 195 & 4,194 & 3.6782 & 0.0066 \\
& Tagged & 0.731 & 0.318 & 192 & 4,187 & 0.6233 & 0.6465 \\
\multirow{2}{*}{ SYC } & Sham & 0.676 & 0.135 & 198 & 4,193 & 4.6324 & 0.0014 \\
& Tagged & 4.176 & 0.762 & 200 & 4,195 & 1.4022 & 0.2347 \\
\hline
\end{tabular}




\subsection{Tag Loss}

All species in this study lost tags. As mentioned previously, there was a high mortality rate in this experiment. If the tag loss analyses had included fish that died within 24 hours of the lost tag, the tag loss rate would have been $1.81 \%$ for all implanted fish-more specifically $2.10 \%$ for $\mathrm{YCH}, 1.33 \%$ for STH, and $2.01 \%$ for SYC (Table 3.13). However, it was obvious from the various types of and responses to infections (e.g., abdominal ulcerations through the body wall and fungal infections that innervated the pericardial window, both greatly decreasing the integrity of the body wall) that moribund or dead fish lost tags at accelerated rates compared to healthy fish. Therefore, tag loss was calculated from fish that survived to 30 days rather than including fish removed from the experiment in a moribund stage or dead.

Tag loss rates were calculated for fish that survived until termination (i.e., 30 days), even if the remaining fish had visible infections. Using this approach, AT loss occurred in $0.62 \%$ of all implanted fish that survived 30 days $(\mathrm{N}=74 \mathrm{YCH}, 40 \mathrm{STH}, 48 \mathrm{SYC}$; Tables 3.13, 3.14)-more specifically, $0.00 \%$ for $\mathrm{YCH}, 0.00 \%$ for STH, and $2.08 \%$ for SYC. PIT-tag loss occurred in $0.59 \%$ of all implanted fish that survived 30 days - more specifically, $0.70 \%$ for $\mathrm{YCH}, 2.78 \%$ in $\mathrm{STH}$, and $0.00 \%$ in SYC.

The low occurrence of lost tags (PIT $\mathrm{N}=2[1 \mathrm{YCH}$ and $1 \mathrm{STH}]$, and $\mathrm{AT} \mathrm{N}=1$ [SYC]) precluded statistical analyses (with acceptable statistical power) of the relationship between lost tags and tag burden. For the fish that lost PIT tags, the mean tag burden for $\mathrm{YCH}$ was $0.32 \%$ and for STH it was $0.14 \%$ for their respective weeks $(05 / 30$ and 05/16). The individual fish tag burdens for PIT tags lost were $0.29 \%$ for the YCH and $1.23 \%$ for the STH. For the single SYC that lost an AT, the week mean tag burden was $4.27 \%$, and the individual's tag burden was $4.02 \%$.

Mechanisms of PIT and AT loss were difficult to discern in dead fish because the surrounding tissue often was deteriorated. In cases where a fish was moribund and removed from the experiment, the AT and PIT tags were noted to be encapsulated by a thin membrane of tissue, adhered to the intestine or body wall, integrated into the pyloric ceacae, or adjacent to pressure necrosis in the spleen and body wall tissue.

Table 3.13. Details on the AT and PIT Tags Lost During the Study. Because of the high rate of infection and mortality during this experiment, tags were not considered shed if the fish died within 24 hours of tag recovery.

\begin{tabular}{|c|c|c|c|c|c|c|c|c|c|}
\hline & Surgery Date & Species & Treatment & $\mathrm{FL}(\mathrm{mm})$ & WW $(\mathrm{g})$ & Days Retained & Mortality (hr) & PIT & AT \\
\hline \multirow{12}{*}{ 泀 } & $5 / 9 / 2010$ & YCH & Tagged & 126 & 17.2 & 18 & $<24$ & $\mathrm{Y}$ & \\
\hline & $5 / 16 / 2010$ & STH & Sham & 223 & 84.5 & 11 & $<24$ & $\mathrm{Y}$ & \\
\hline & $5 / 16 / 2010$ & STH & Tagged & 180 & 41.9 & 03 & NA & $\mathrm{Y}$ & \\
\hline & $5 / 23 / 2010$ & STH & Tagged & 220 & 78.0 & 06 & $<24$ & $\mathrm{Y}$ & \\
\hline & $5 / 30 / 2010$ & $\mathrm{YCH}$ & Sham & 143 & 29.3 & 18 & NA & $\mathrm{Y}$ & \\
\hline & $5 / 30 / 2010$ & $\mathrm{YCH}$ & Sham & 123 & 16.8 & 20 & $<24$ & $\mathrm{Y}$ & \\
\hline & $5 / 30 / 2010$ & $\mathrm{YCH}$ & Sham & 161 & 39.6 & 20 & $<24$ & $\mathrm{Y}$ & \\
\hline & $5 / 30 / 2010$ & $\mathrm{YCH}$ & Sham & 143 & 27.1 & 21 & $<24$ & $\mathrm{Y}$ & \\
\hline & $5 / 30 / 2010$ & $\mathrm{YCH}$ & Sham & 134 & 20.6 & 21 & $<24$ & $\mathrm{Y}$ & \\
\hline & $5 / 30 / 2010$ & $\mathrm{YCH}$ & Tagged & 127 & 20.2 & 15 & $<24$ & $\mathrm{Y}$ & \\
\hline & $5 / 30 / 2010$ & $\mathrm{YCH}$ & Tagged & 153 & 32.2 & 28 & $<24$ & $\mathrm{Y}$ & \\
\hline & $5 / 30 / 2010$ & STH & Tagged & 221 & 81.3 & 20 & $<24$ & $\mathrm{Y}$ & $\mathrm{Y}$ \\
\hline
\end{tabular}


Table 3.13. (contd)

\begin{tabular}{|c|c|c|c|c|c|c|c|c|c|}
\hline & Surgery Date & Species & Treatment & $\mathrm{FL}(\mathrm{mm})$ & WW (g) & Days Retained & Mortality (hr) & PIT & AT \\
\hline \multirow{7}{*}{ 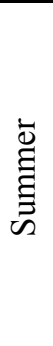 } & $6 / 13 / 2010$ & $\overline{\text { SYC }}$ & Tagged & 109 & 12.4 & 7 & $<24$ & $\mathrm{Y}$ & \\
\hline & $6 / 20 / 2010$ & SYC & Sham & 106 & 10.9 & 17 & $<24$ & $\mathrm{Y}$ & \\
\hline & $6 / 20 / 2010$ & SYC & Tagged & 111 & 12.0 & 30 & $<24$ & $\mathrm{Y}$ & $\mathrm{Y}$ \\
\hline & $6 / 20 / 2010$ & SYC & Tagged & 109 & 11.0 & 30 & $<24$ & & $\mathrm{Y}$ \\
\hline & $6 / 27 / 2010$ & SYC & Tagged & 112 & 13.6 & 22 & $<24$ & & $\mathrm{Y}$ \\
\hline & $7 / 4 / 2010$ & SYC & Tagged & 107 & 10.3 & 08 & $<24$ & & $\mathrm{Y}$ \\
\hline & $7 / 4 / 2010$ & SYC & Tagged & 109 & 12.8 & 21 & NA & & $\mathrm{Y}$ \\
\hline
\end{tabular}

$\mathrm{FL}=$ fork length; $\mathrm{WW}=$ wet weight.

Table 3.14. Acoustic and PIT-Tag Loss Percentages for the Fish that Survived for 30 Days. The table includes the complete tag loss list including those fish that died or were removed, and then only tag lost from fish that survived.

\begin{tabular}{|c|c|c|c|c|c|c|}
\hline & $\begin{array}{c}\text { Tag Loss } \\
\text { Type } \\
\end{array}$ & $\begin{array}{c}\text { \# of Surgically } \\
\text { Implanted Fish } \\
(\underline{30-\text { day }} \\
\text { survival })\end{array}$ & $\begin{array}{c}\text { \# of Tags Lost } \\
\text { Including } \\
\text { Mortalities }\end{array}$ & $\begin{array}{c}\text { \% Tags Lost } \\
\text { Including } \\
\text { Mortalities }\end{array}$ & $\begin{array}{c}\text { \# of Tags } \\
\text { Expelled from } \\
\text { Fish at } 30 \text { days } \\
\end{array}$ & $\begin{array}{c}\% \text { Tags } \\
\text { Expelled from } \\
\text { Fish at } 30 \text { days }\end{array}$ \\
\hline \multirow{3}{*}{$\underset{\nu}{ \pm}$} & Overall & $381(143)$ & 8 & 2.10 & 1 & 0.70 \\
\hline & PIT & $381(69)$ & 8 & 2.10 & 1 & 0.70 \\
\hline & $\mathrm{AT}$ & $194(74)$ & 0 & 0.00 & 0 & 0.00 \\
\hline \multirow{3}{*}{$\underset{⿱ 乛}{E}$} & Overall & $376(76)$ & 5 & 1.33 & 1 & 1.32 \\
\hline & PIT & $376(36)$ & 4 & 1.06 & 1 & 2.78 \\
\hline & $\mathrm{AT}$ & $192(40)$ & 1 & 0.52 & 0 & 0.00 \\
\hline \multirow{3}{*}{ 它 } & Overall & $398(122)$ & 8 & 2.01 & 1 & 0.82 \\
\hline & PIT & $398(74)$ & 3 & 0.75 & 0 & 0.00 \\
\hline & $\mathrm{AT}$ & $200(48)$ & 5 & 2.50 & 1 & 2.08 \\
\hline
\end{tabular}

\subsection{Surgeon Performance}

Fish mortality rates for individual surgeons (based on the number of fish per species each surgeon implanted) ranged from 52 to $88 \%$. For $\mathrm{YCH}$, Surgeon $\mathrm{C}$ had the highest fish mortality rate, $67 \%$, while Surgeon $\mathrm{G}$ had the lowest fish mortality rate, 56\%. Conversely, for STH Surgeon G had the highest fish mortality rate, $88 \%$, and Surgeon $\mathrm{C}$ had the lowest fish mortality rate, $72 \%$. During the summer, Surgeon $\mathrm{D}$ had the lowest fish mortality rate, $52 \%$, while Surgeon $\mathrm{G}$ had the highest fish mortality rate, $75 \%$. Using Chi-square likelihood ratio, there were no significant differences among surgeons for each species (all $p \geq 0.135$; Table 3.15).

AT or PIT tags expelled, including the tags of fish found dead within 24 hours, were implanted by six of the eight surgeons (Table 3.16). Excluding the AT or PIT tags recovered within 24 hours of fish mortality, one AT and two PIT tags recovered were implanted by two of the eight surgeons (Table 3.17). 
The low occurrence of the expelled AT and PIT tags (i.e., those expelled by fish not found dead within 24 hours) precluded meaningful statistical analyses of surgeon effect on tag expulsion.

Table 3.15. Number and Percentage of Mortalities and Chi-Square Results. The calculated percentages of mortalities based on the total fish by species for each surgeon are provided.

\begin{tabular}{|c|c|c|c|c|c|c|}
\hline & Surgeon Code & Species & $\begin{array}{c}\text { Overall Mortalities } \\
\mathrm{N}(\% \text { of total implanted })\end{array}$ & $\mathrm{df}$ & $X^{2}$ & $p$ \\
\hline \multirow{15}{*}{ 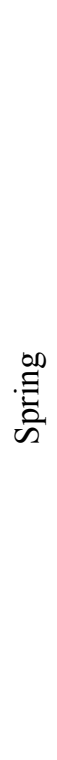 } & A & $\mathrm{YCH}$ & $30(59)$ & 6 & 5.04 & 0.7664 \\
\hline & B & $\mathrm{YCH}$ & $41(66)$ & & & \\
\hline & $\mathrm{C}$ & $\mathrm{YCH}$ & $35(67)$ & & & \\
\hline & $\mathrm{D}$ & $\mathrm{YCH}$ & - & & & \\
\hline & E & $\mathrm{YCH}$ & $33(62)$ & & & \\
\hline & $\mathrm{F}$ & $\mathrm{YCH}$ & $52(58)$ & & & \\
\hline & G & $\mathrm{YCH}$ & $47(56)$ & & & \\
\hline & $\mathrm{H}$ & $\mathrm{YCH}$ & - & & & \\
\hline & A & STH & $38(78)$ & 5 & 8.41 & 0.1349 \\
\hline & B & STH & $48(79)$ & & & \\
\hline & $\mathrm{C}$ & STH & $36(72)$ & & & \\
\hline & $\mathrm{D}$ & STH & - & & & \\
\hline & $\mathrm{E}$ & STH & $37(73)$ & & & \\
\hline & $\mathrm{F}$ & STH & $64(73)$ & & & \\
\hline & G & STH & $77(88)$ & & & \\
\hline \multirow{9}{*}{ 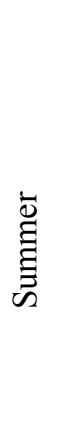 } & $\mathrm{H}$ & STH & - & & & \\
\hline & A & SYC & $38(73)$ & 6 & 3.33 & 0.5394 \\
\hline & B & SYC & $43(68)$ & & & \\
\hline & $\mathrm{C}$ & SYC & $63(72)$ & & & \\
\hline & $\mathrm{D}$ & SYC & $11(52)$ & & & \\
\hline & E & SYC & - & & & \\
\hline & $\mathrm{F}$ & SYC & $43(65)$ & & & \\
\hline & G & SYC & $45(75)$ & & & \\
\hline & $\mathrm{H}$ & SYC & $33(67)$ & & & \\
\hline
\end{tabular}


Table 3.16. Number of Expelled Acoustic Transmitters and PIT Tags by Surgeon. The "Total SI Fish" column shows the actual number of fish that were surgically implanted by each surgeon.

\begin{tabular}{|c|c|c|c|c|c|c|}
\hline & Surgeon & Species & Total SI Fish & PIT Loss & AT Loss & $\begin{array}{c}\text { Loss Excluding }<24-\mathrm{hr} \\
\text { Mortalities }\end{array}$ \\
\hline \multirow{14}{*}{$\begin{array}{l}\text { Dी } \\
\text { की }\end{array}$} & $\mathrm{A}$ & $\mathrm{YCH}$ & 51 & - & - & - \\
\hline & B & $\mathrm{YCH}$ & 62 & 2 & - & - \\
\hline & $\mathrm{C}$ & $\mathrm{YCH}$ & 52 & - & - & - \\
\hline & D & $\mathrm{YCH}$ & NA & - & - & - \\
\hline & E & $\mathrm{YCH}$ & 54 & 1 & - & - \\
\hline & $\mathrm{F}$ & $\mathrm{YCH}$ & 89 & 1 & - & - \\
\hline & G & $\mathrm{YCH}$ & 84 & 4 & - & $1 \mathrm{PIT}$ \\
\hline & $\mathrm{H}$ & $\mathrm{YCH}$ & NA & - & - & - \\
\hline & A & STH & 49 & - & - & - \\
\hline & B & STH & 61 & 2 & 1 & $1 \mathrm{PIT}$ \\
\hline & $\mathrm{C}$ & STH & 50 & - & - & - \\
\hline & D & STH & NA & - & - & - \\
\hline & E & STH & 51 & 1 & - & - \\
\hline & $\mathrm{F}$ & STH & 88 & 1 & - & - \\
\hline \multirow{10}{*}{ 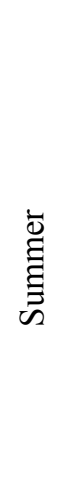 } & G & STH & 88 & - & - & - \\
\hline & $\mathrm{H}$ & STH & NA & - & - & - \\
\hline & A & SYC & 52 & - & 1 & - \\
\hline & B & SYC & 63 & 1 & 2 & $1 \mathrm{AT}$ \\
\hline & $\mathrm{C}$ & SYC & 87 & - & - & - \\
\hline & D & SYC & 21 & - & - & - \\
\hline & E & SYC & NA & - & - & - \\
\hline & $\mathrm{F}$ & SYC & 66 & 1 & - & - \\
\hline & G & SYC & 60 & - & 1 & - \\
\hline & $\mathrm{H}$ & SYC & 49 & 1 & 1 & - \\
\hline
\end{tabular}

Table 3.17. PIT and/or AT Loss Standardized by Surgeon Effort

\begin{tabular}{cccccc}
\hline Surgeon & Total SI fish & AT/PIT-Tag Loss & \% Loss & $\begin{array}{c}\text { AT/PIT-Tag Loss excluding } \\
<24 \text { hr mortalities }\end{array}$ & $\begin{array}{c}\text { \% Loss excluding } \\
<24 \text { hr mortalities }\end{array}$ \\
\hline A & 152 & 1 & 0.7 & 0 & 0 \\
B & 186 & 8 & 4.3 & 2 & 1.1 \\
C & 187 & 0 & 0 & 0 & 0 \\
D & 21 & 0 & 0 & 0 & 0 \\
E & 105 & 2 & 1.9 & 0 & 0 \\
F & 243 & 3 & 1.2 & 0 & 0.42 \\
G & 238 & 5 & 2.1 & 1 & 0 \\
H & 48 & 2 & 4.2 & 0 & \\
\hline
\end{tabular}




\subsection{Mortality Curves}

Mortality curves for the spring and summer study sessions are provided in Figures 3.2 through 3.16. The figures show fish loss during the 30-day holding periods; they do not include the excluded fish from Table 3.1.

\subsubsection{Spring Session}

For Week 1, YCH and STH (Figures 3.2 and 3.3, respectively) received treatment (Tagged, Sham, or Control) on 05/02/2010, arrived at the BON SMF on 05/03/2010, and were released on 06/01/2010

(30 days). For STH, 50\% mortality occurred on Day 13. The last YCH death occurred on Day 29 and the last STH death occurred on Day 28. No AT or PIT tags were expelled.

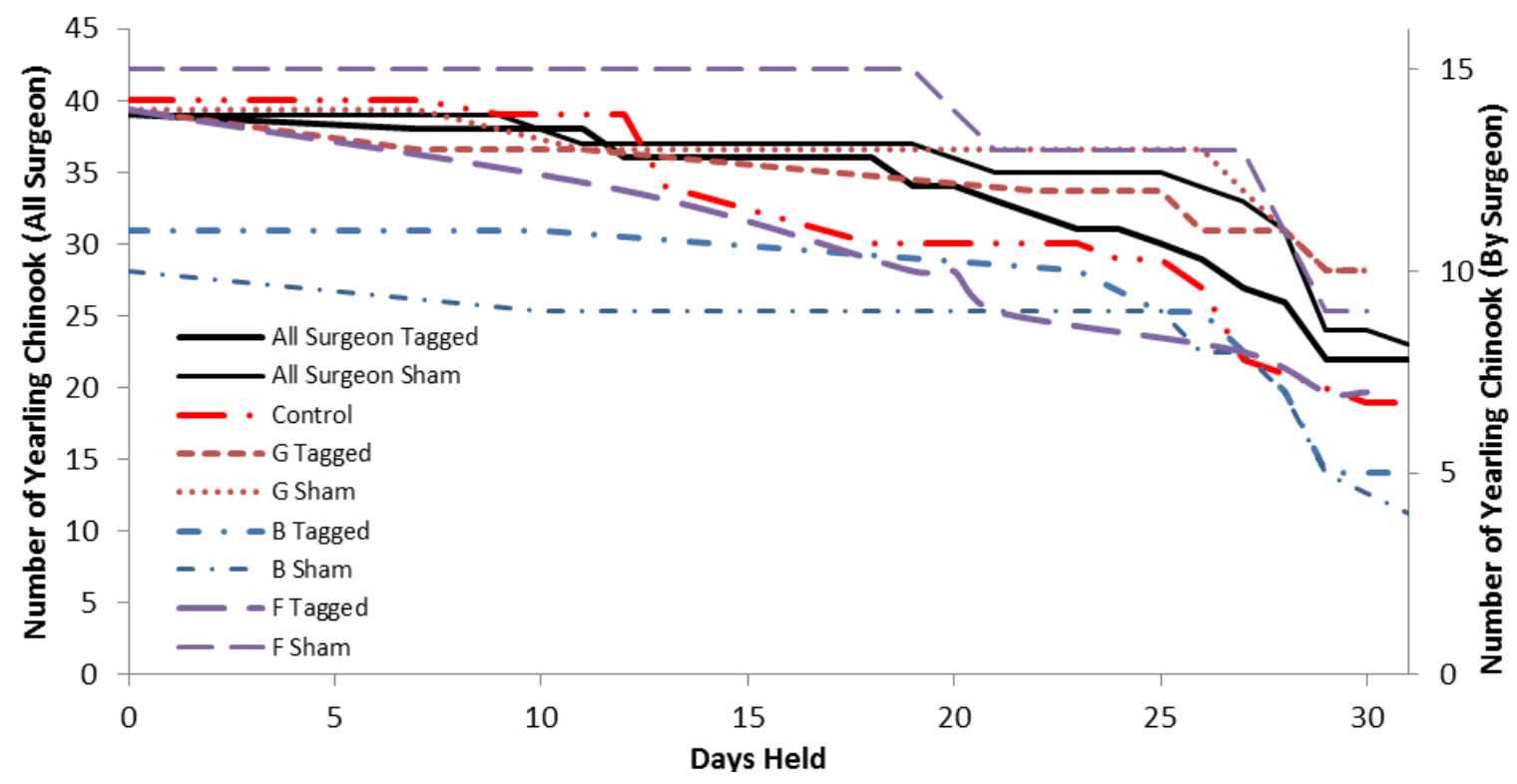

Figure 3.2. Week 1 YCH Fish Mortality 


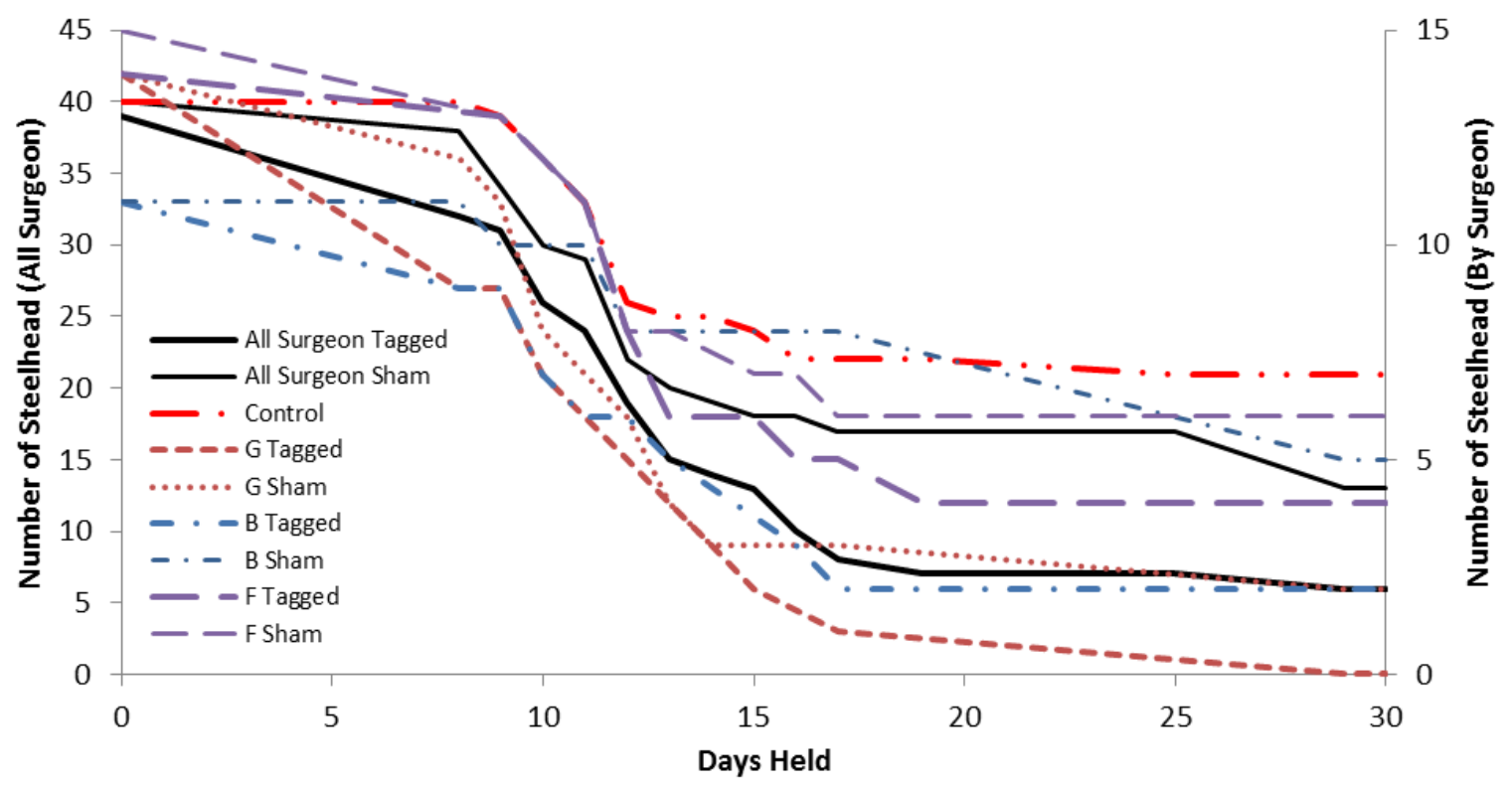

Figure 3.3. Week 1 STH Fish Mortality

During Week 2, YCH and STH (Figures 3.4 and 3.5, respectively) received treatment on 05/09/2010, arrived at the BON SMF on 05/10/2010, and were released on 06/08/2010 (30 days). For YCH, 50\% mortality occurred on Day 28; for STH, 50\% mortality occurred on Day 13 . The last fish deaths were on Day 29 for YCH and on Day 25 for STH. One PIT tag was expelled on Day 18, which was within 24 hours of the fish mortality.

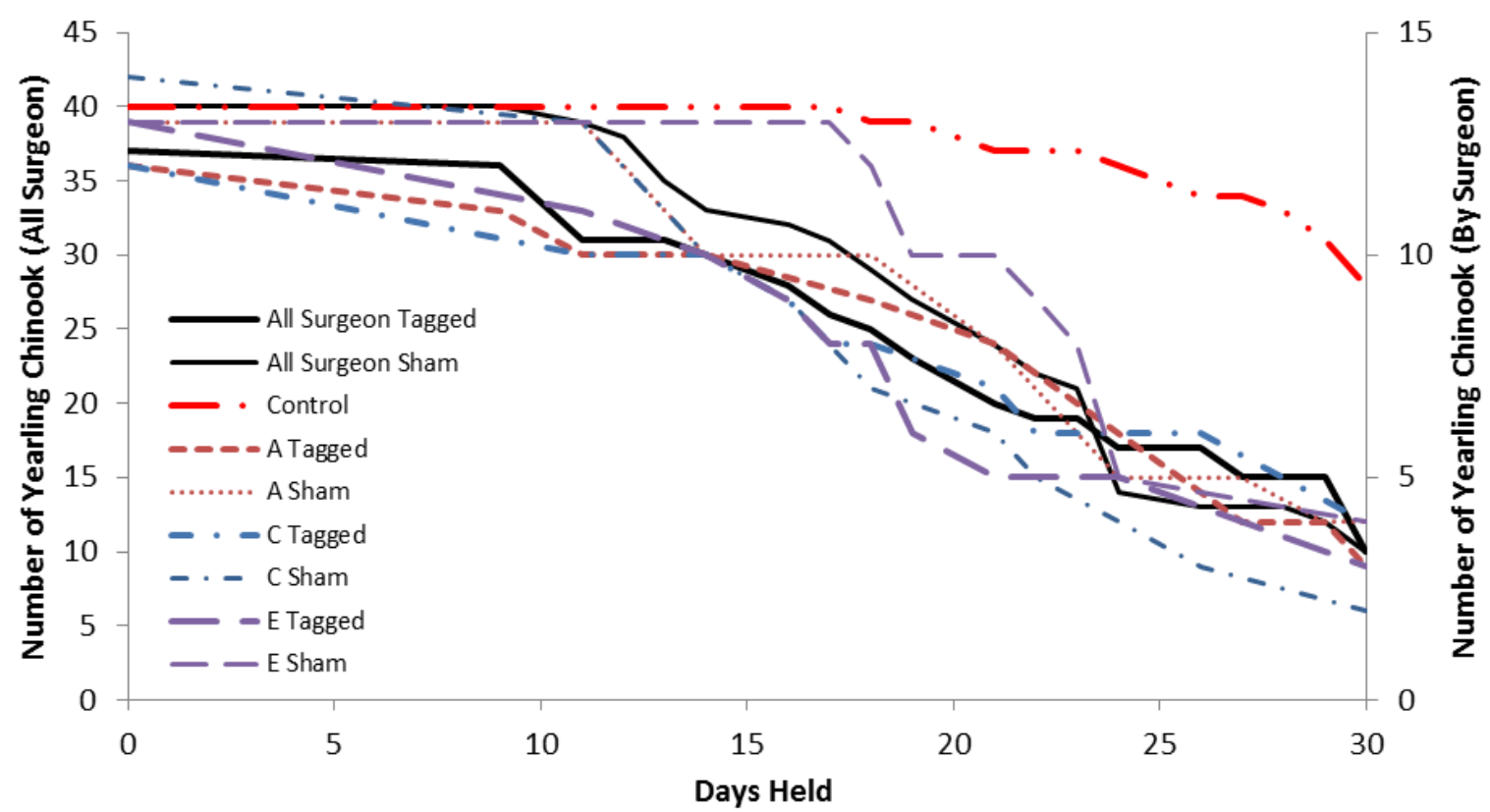

Figure 3.4. Week 2 YCH Fish Mortality 


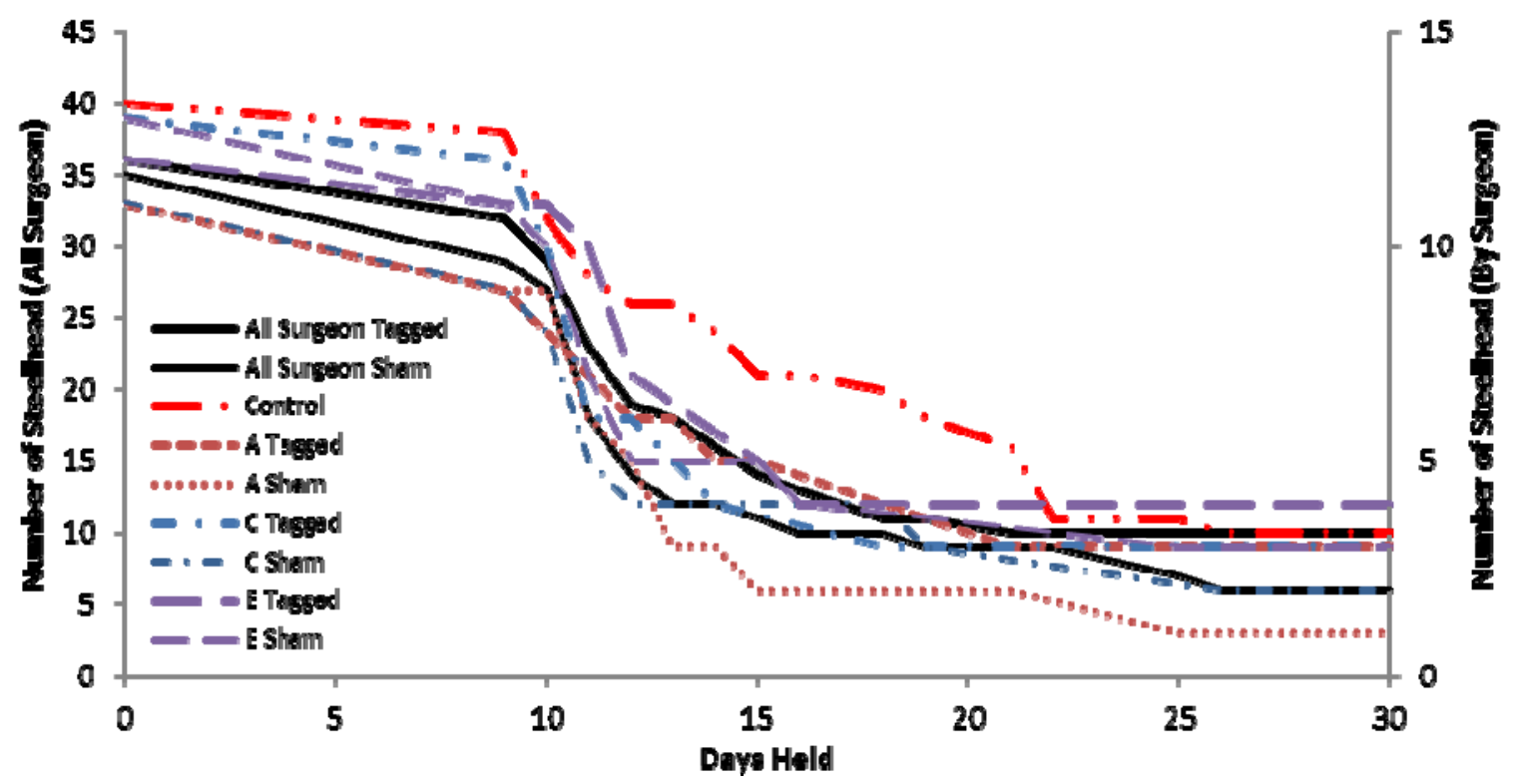

Figure 3.5. Week 2 STH Fish Mortality

During Week 3, YCH and STH (Figures 3.6 and 3.7, respectively) received treatment on 05/16/2010, arrived at the BON SMF on 05/17/2010, and were released on 06/15/2010 (30 days). For YCH, 50\% mortality occurred on Day 28; for STH, 50\% mortality occurred on Day 9. The last fish deaths were on Day 29 for YCH and on Day 17 for STH. Two PIT tags were expelled from STH on Day 3 and Day 11. The earlier tag was expelled 5 days before the STH was necropsied. The second STH was necropsied within 24 hours of the tag expulsion.

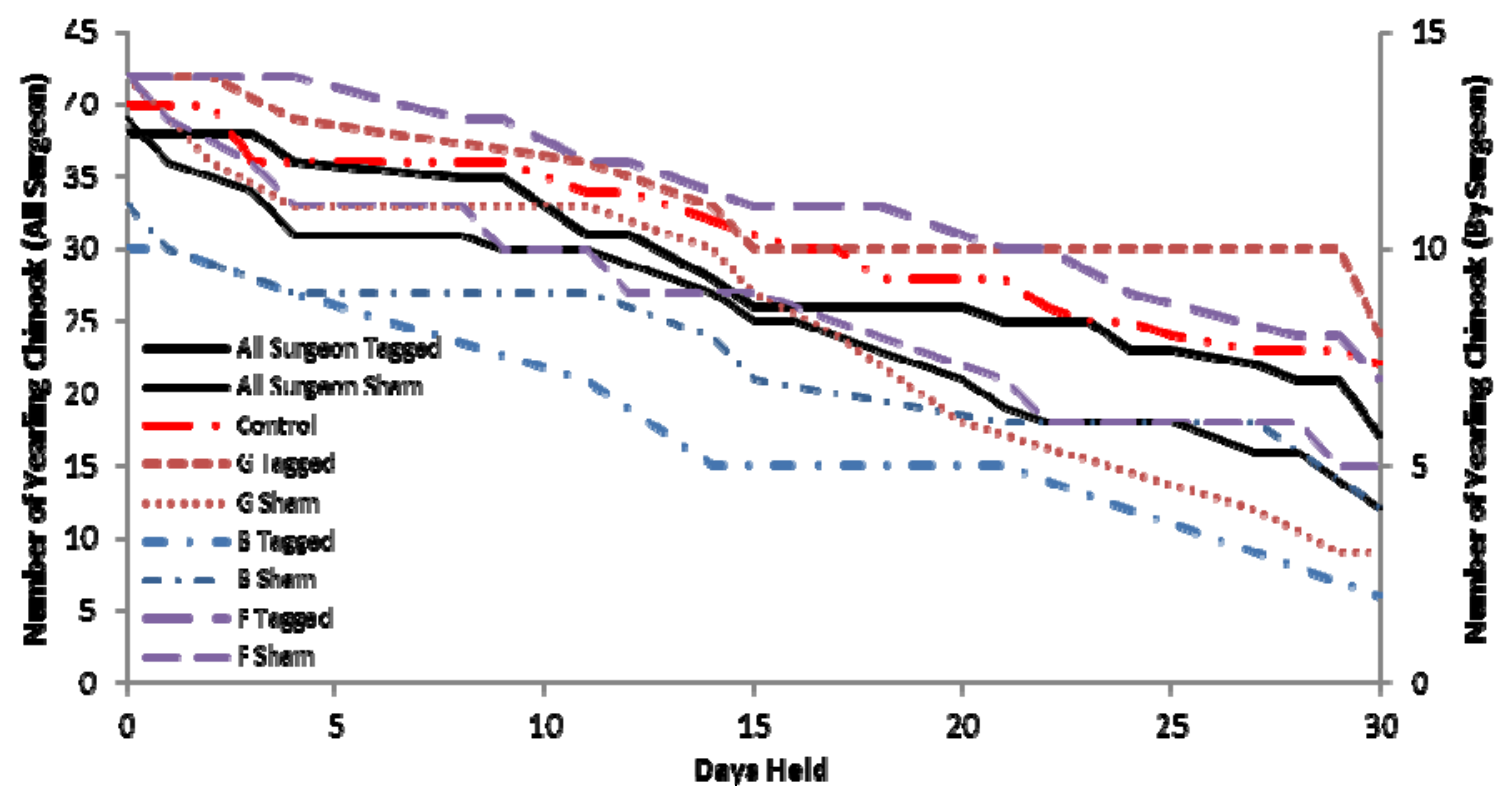

Figure 3.6. Week 3 YCH Fish Mortality 


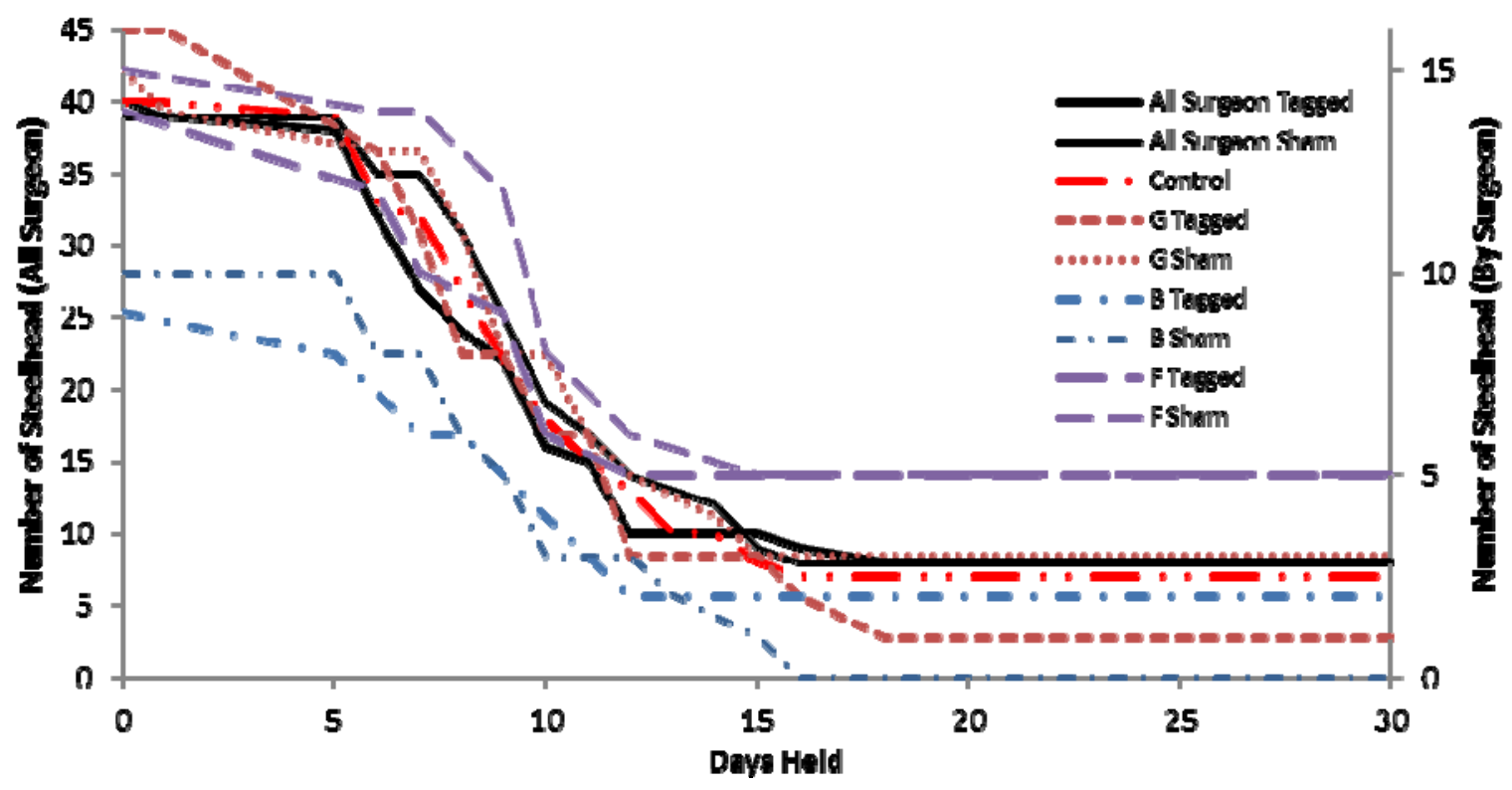

Figure 3.7. Week 3 STH Fish Mortality

During Week 4, YCH and STH (Figures 3.8 and 3.9, respectively) received treatment on 05/23/2010, arrived at the BON SMF on 05/24/2010, and were released on 06/22/2010 (30 days). For YCH, 50\% mortality occurred on Day 28; for STH, 50\% mortality occurred on Day 12. The last fish deaths were on Day 28 for YCH and STH. One PIT tag was expelled on Day 6 within 24 hours of the STH mortality.

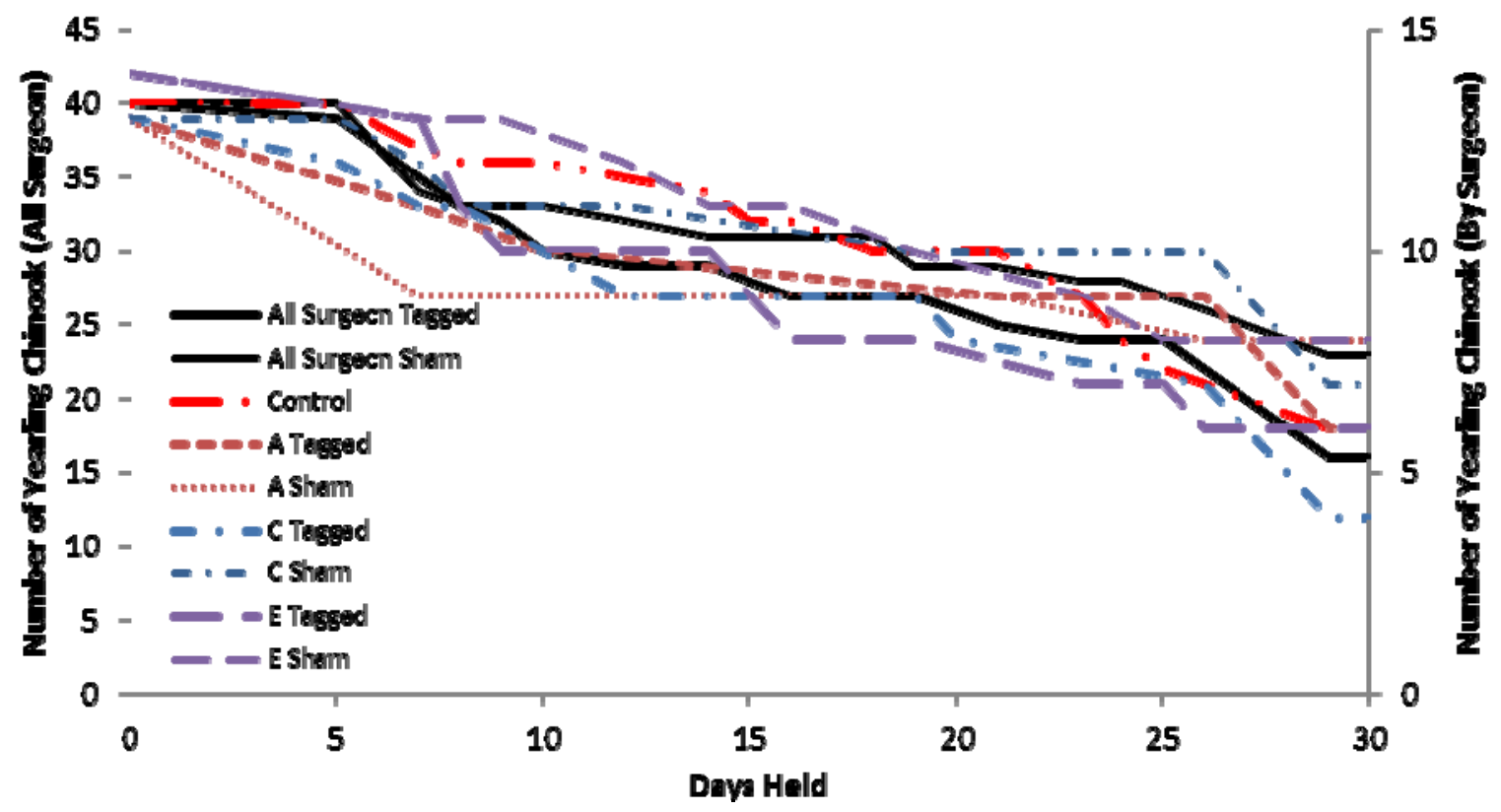

Figure 3.8. Week 4 YCH Fish Mortality 


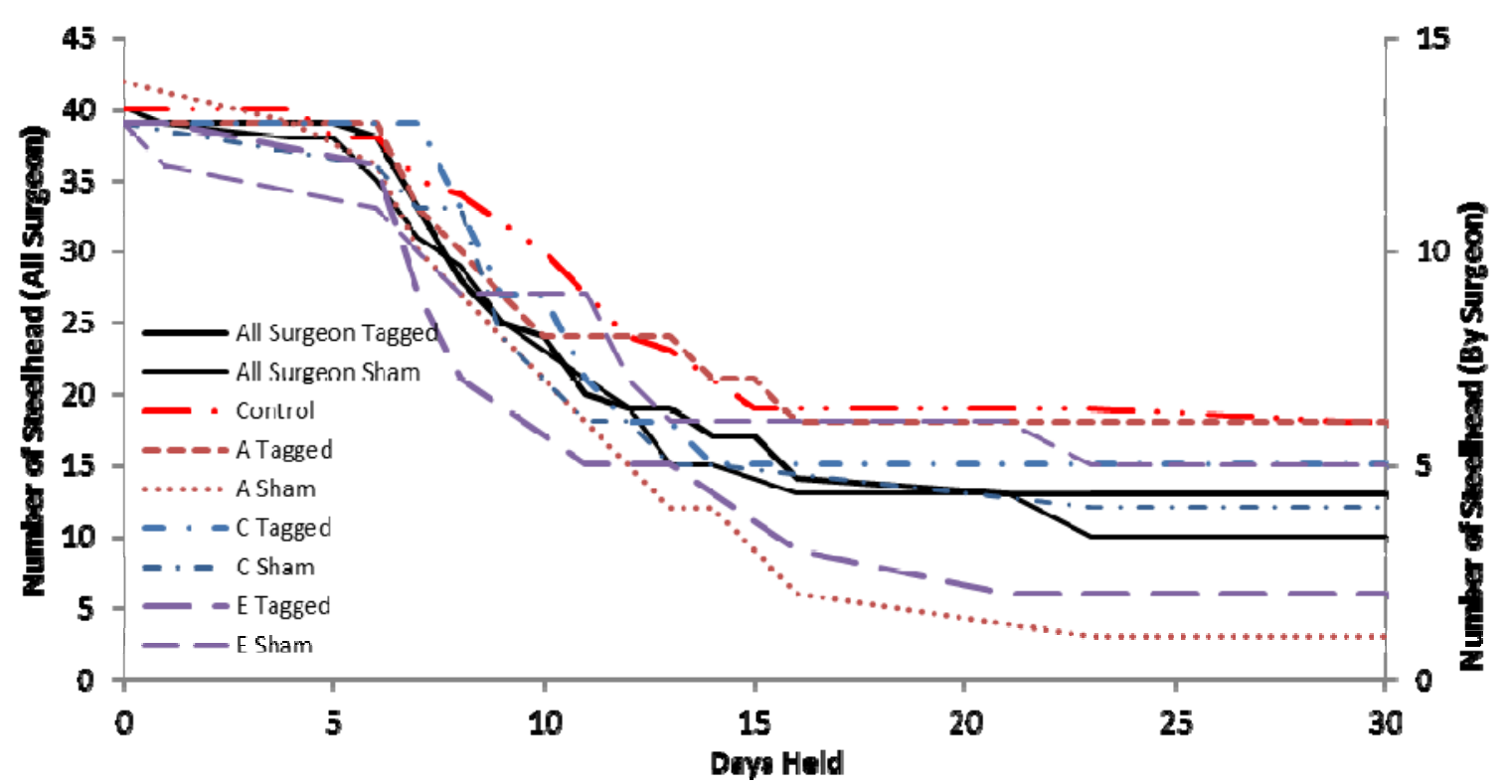

Figure 3.9. Week 4 STH Fish Mortality

During Week 5, YCH and STH (Figures 3.10 and 3.11, respectively) received treatment on 05/30/2010, arrived at the BON SMF on 05/31/2010, and were released on 06/29/2010 (30 days). For $\mathrm{YCH}, 50 \%$ mortality occurred on Day 23; for STH, 50\% mortality occurred on Day 10 . The last fish deaths were on Day 28 for YCH and STH. The YCH group had seven expelled PIT tags: one on Day 15, one on Day 18, two on Day 20, two on Day 21, and one on Day 28. Six of the seven PIT-tag expulsions occurred within 24 hours of YCH mortalities, while one PIT-tag expulsion occurred within 48 hours of the mortality. For the STH, one AT/PIT-tag expulsion occurred within 24 hours of mortality.

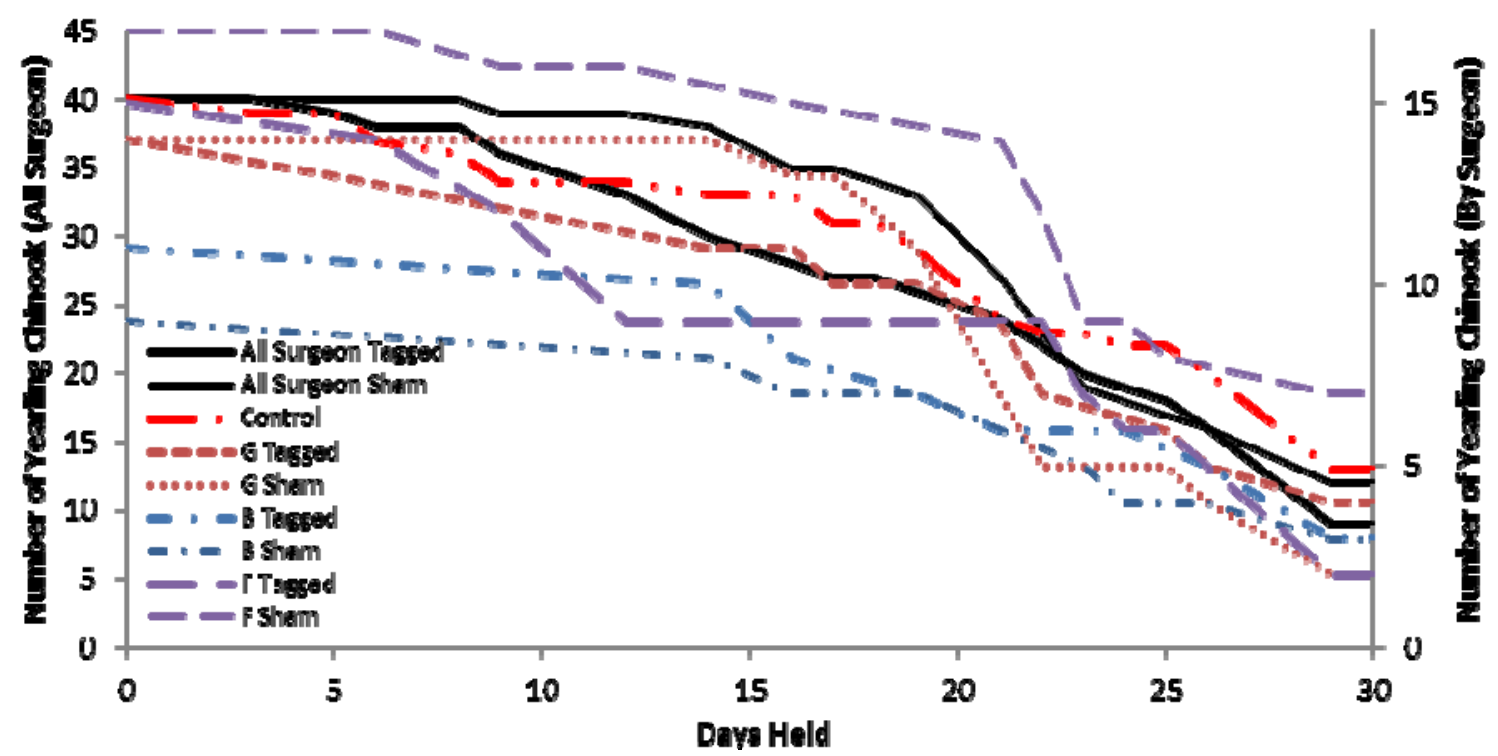

Figure 3.10. Week 5 YCH Fish Mortality 


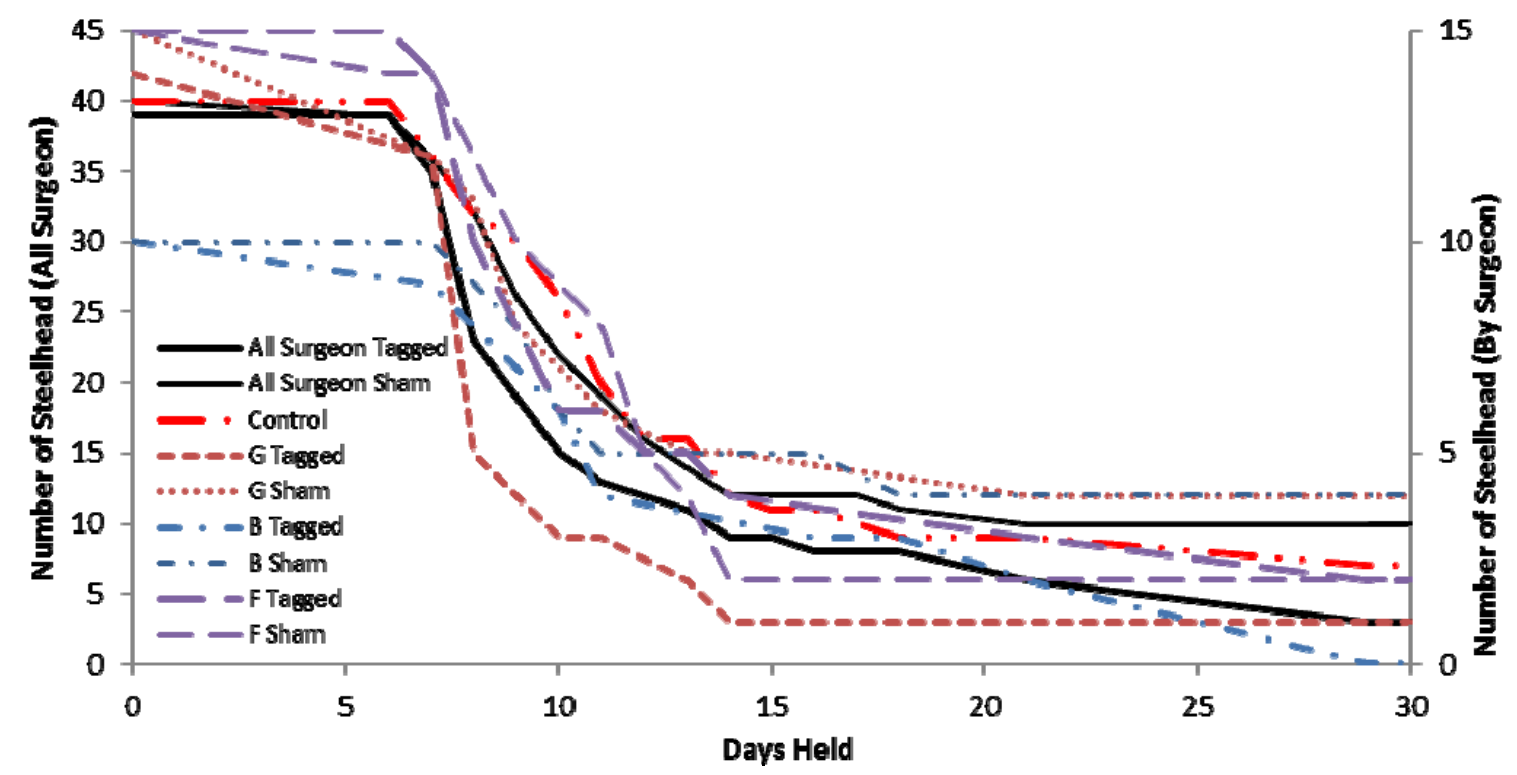

Figure 3.11. Week 5 YCH Fish Mortality

\subsubsection{Summer Session}

During Week 6, SYC (Figure 3.12) received treatment on 06/13/2010, arrived at the BON SMF on $06 / 14 / 2010$, and were released on 07/13/2010 (30 days). For SYC, 50\% mortality occurred on Day 26, the last fish deaths were on Day 29, and there were no AT- or PIT-tag expulsions.

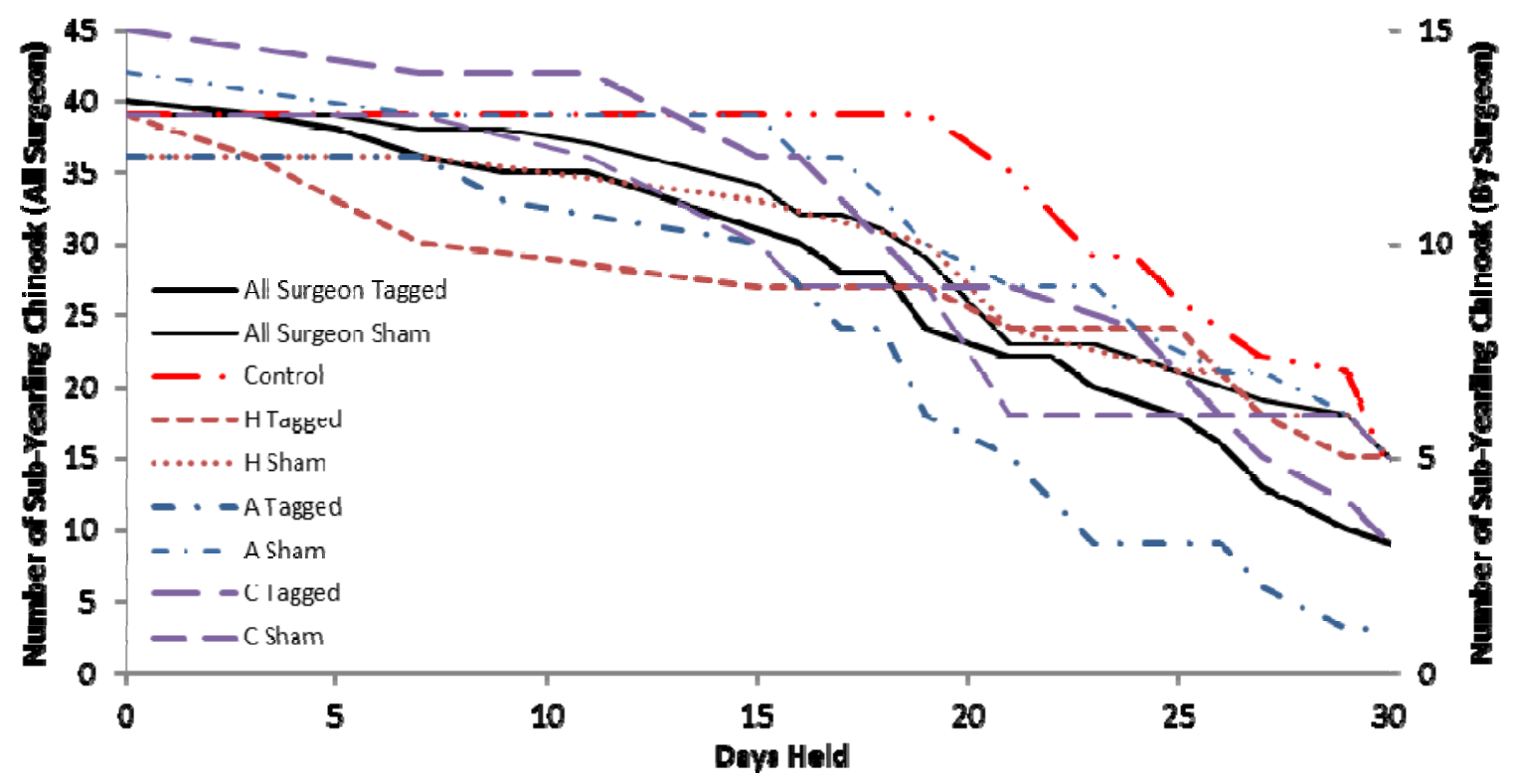

Figure 3.12. Week 6 SYC Fish Mortality

During Week 7, SYC (Figure 3.13) received treatment on 06/20/2010, arrived at the BON SMF on $06 / 21 / 2010$, and were released on 07/21/2010 (31 days). For SYC, 50\% mortality occurred on Day 27 and the last fish deaths were on Day 29. One PIT tag was expelled on Day 18, AT/PIT tags from 
one individual fish were expelled on Day 30, and one AT was expelled on Day 30. All expulsions occurred within 24 hours of the fish mortalities.

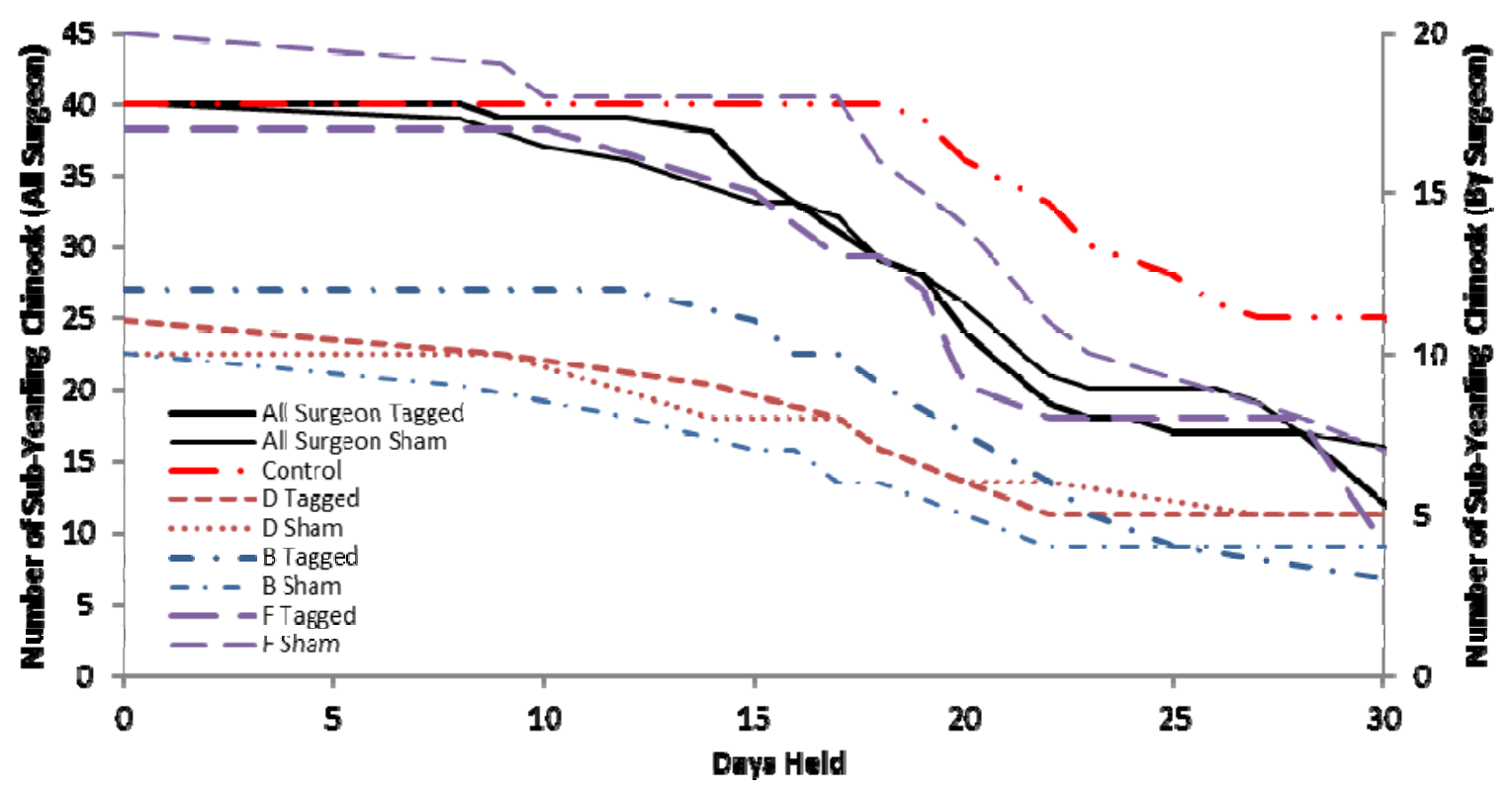

Figure 3.13. Week 7 SYC Fish Mortality

During Week 8, SYC (Figure 3.14) received treatment on 06/27/2010, arrived at the BON SMF on $06 / 28 / 2010$, and were released on 07/27/2010 (30 days). For SYC, 50\% mortality occurred on Day 22, the last fish deaths were on Day 29, and on Day 22 one AT was expelled within 24 hours of the fish mortality.

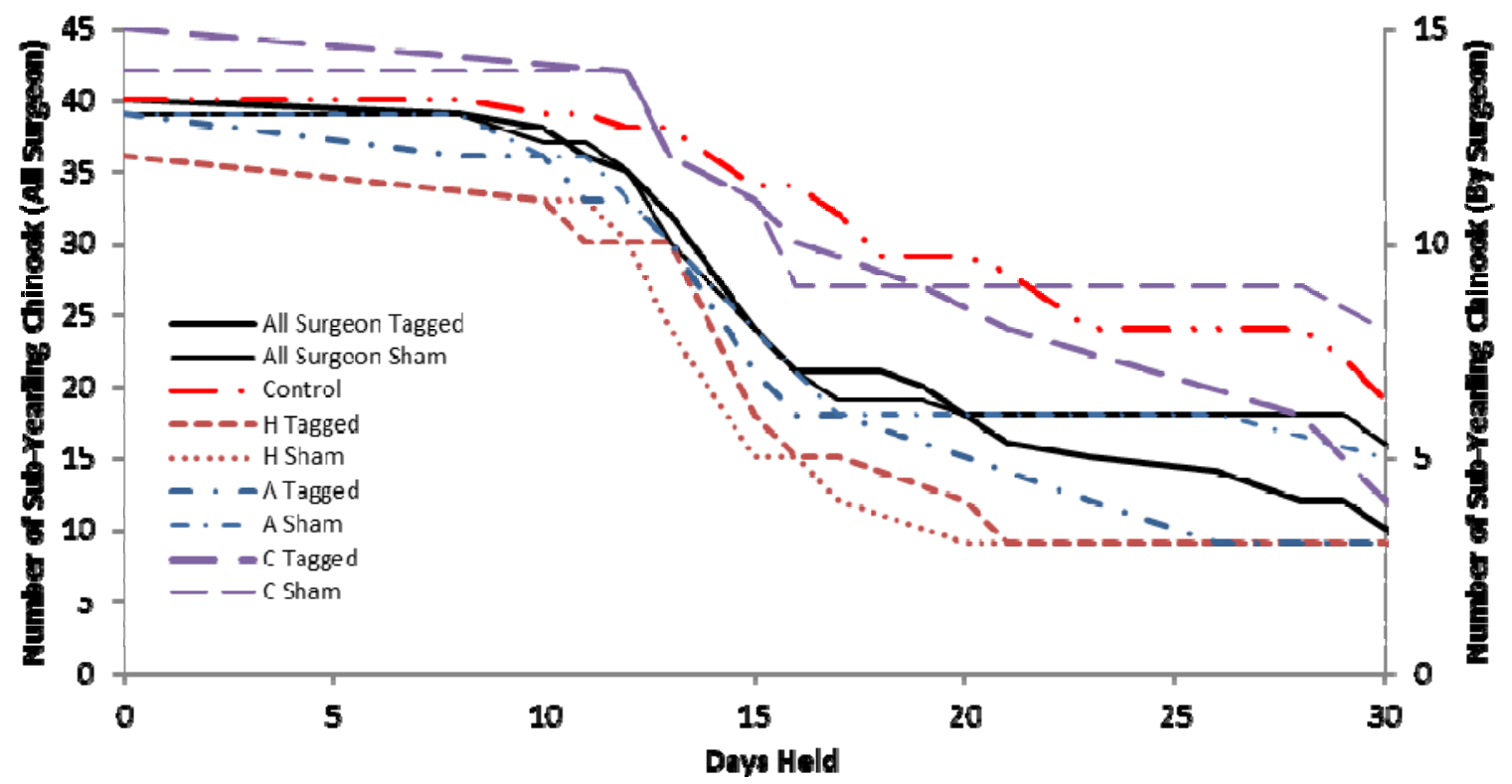

Figure 3.14. Week 8 SYC Fish Mortality 
During Week 9, SYC (Figure 3.15) received treatment on 07/04/2010, arrived at the BON SMF on 07/05/2010, and were released on 08/03/2010 (30 days). For SYC, 50\% mortality occurred on Day 18 and the last fish deaths were on Day 29. Two fish expelled their ATs; one on Day 8 (within 24 hours of the fish mortality), and the other on Day 21. The latter fish was released at the end of the 30 days ( 8 days after the tag expulsion).

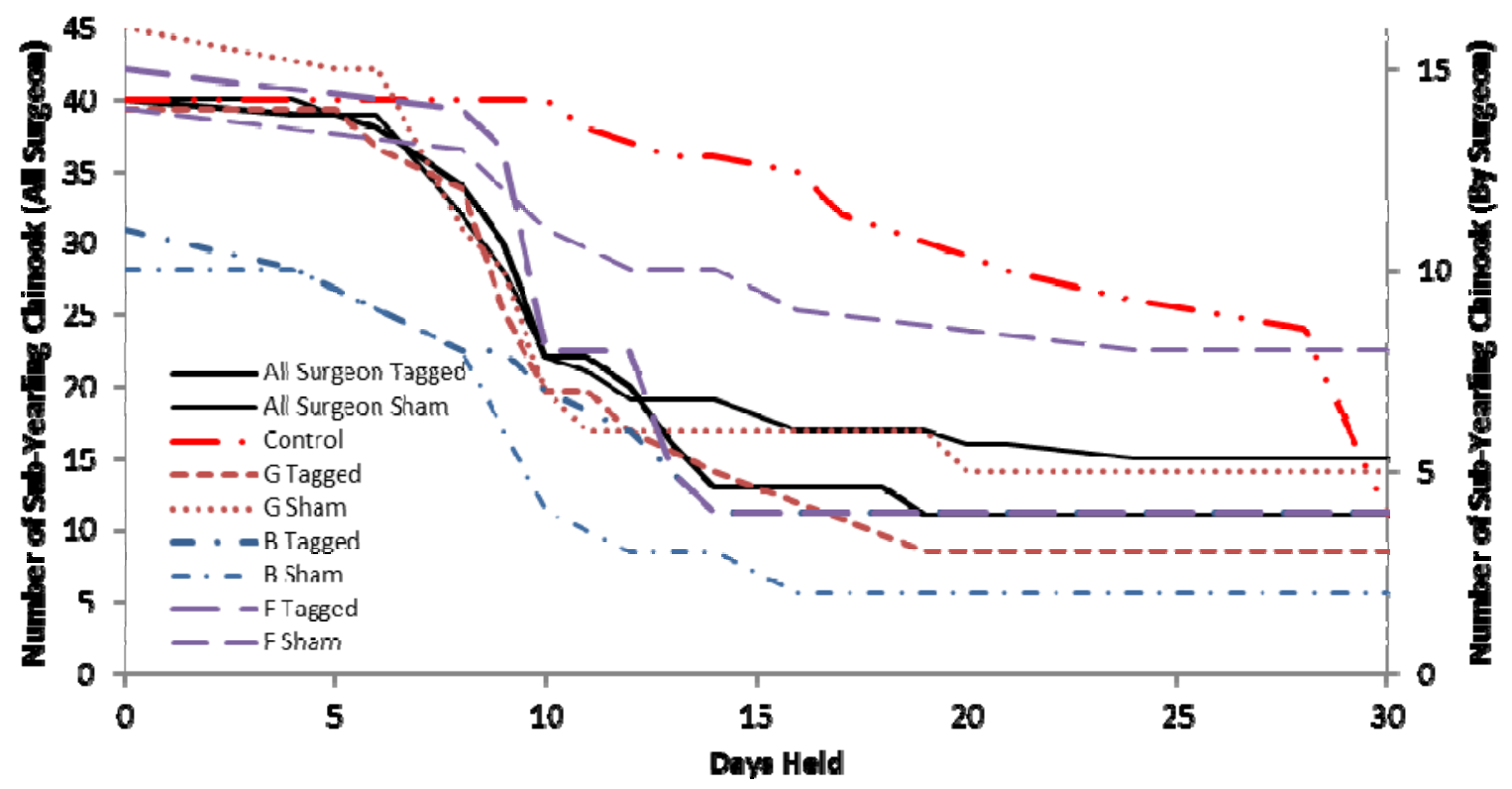

Figure 3.15. Week 9 SYC Fish Mortality

During Week 10, SYC (Figure 3.16) received treatment on 07/11/2010, arrived at the BON SMF on 07/12/2010, and were released on 08/10/2010. For SYC, 50\% mortality occurred on Day 7, the last fish deaths were on Day 27, and there were no AT- or PIT-tag expulsions.

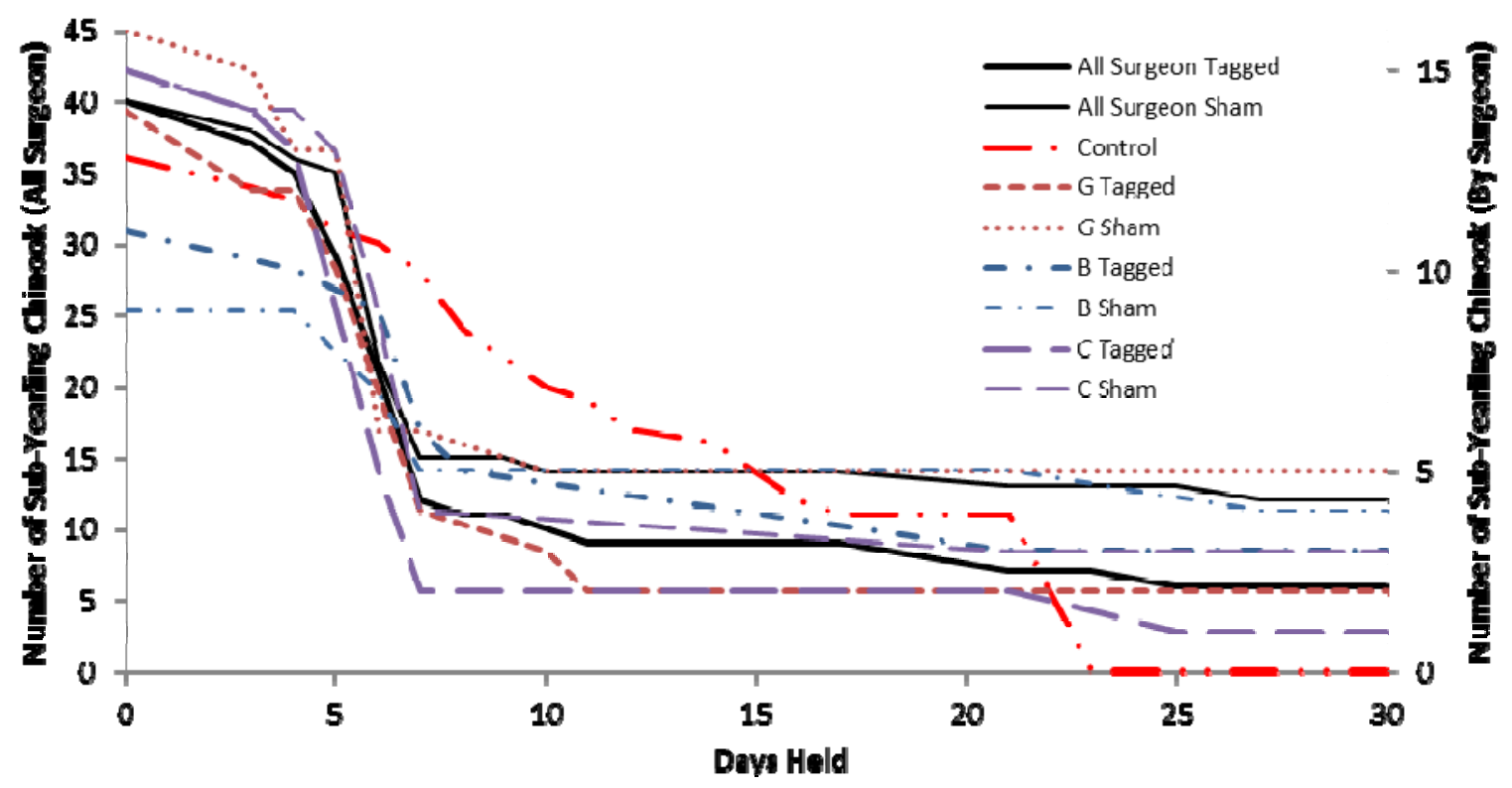

Figure 3.16. Week 10 SYC Fish Mortality 



\subsection{Discussion}

Studies of fish movement patterns using telemetry are often subjected to biases from the technology itself and/or the handling and surgery events associated with tagging. Past studies have shown that technology, gear, species, fish handling, surgeon training, and environmental conditions are confounding factors, and thus hamper researchers' abilities to design future studies, develop standardized sampling protocols, and, most importantly, they can greatly affect biotelemetry and survival model assumptions (Wagner et al. 2000; Welch et al. 2007; McCormick et al. 2009; Cooke et al. 2011). The unifying tenet of these assumptions is that intra-coelomic implanted fish should have the same behaviors, survival rates, and physiological costs as un-implanted fish (Skalski 1998, 2002). Currently, it is hypothesized that juvenile salmonids can be more susceptible to physiological and behavioral changes when implanted with transmitters because of 1) the energetic costs associated with the transmitter weight ("tag burden"), and 2) the energetic costs and damage associated with the tag and tagging process.

In 2001, the USACE, National Marine Fisheries Service, and PNNL began to develop and rely on JSATS to monitor fish passage throughout the FCRPS. Over the 9 years since its inception, the JSATS receiver and transmitter technology has evolved rapidly. This study was the first to consider tag loss and survivorship in juvenile YCH, STH, and SYC using the smallest JSATS AT available, a balanced design for surgeon effort, and the same fish source as a concurrent study, Lower Columbia River Acoustic-Tag Investigations of Dam Passage Survival and Associated Metrics, 2010 (Carlson et al. in preparation).

$\mathrm{YCH}, \mathrm{STH}$, and SYC tolerated the handling and surgical procedures with no mortalities occurring during implantation of the tags or during the 24-hour recovery stage before transportation; however, seven SYC were moribund or died during the 1.5-hour transportation stage (Table 3.1). Five of the seven fish were in the Control treatment group, one was in the Sham treatment group, and one fish was in the Tagged treatment group. Several hypotheses are proposed to explain the mortalities of SYC in relation to transportation:

- surgeon influence - two SYC implant-caused mortalities involved fish handled by the same surgeon

- seasonal effect - seven SYC were predisposed to transportation stress because of their physiological state and the elevated ambient water temperature

- oxygen deprivation - if the oxygen meter was not correctly calibrated, drivers may have been misled about actual dissolved oxygen levels.

The surgeon influence hypothesis considers only two mortalities, and cannot explain the other five mortalities; thus, it is a weak hypothesis. The seasonal effect should have occurred with transportation mortalities being significantly greater at the end of the season than at the beginning of the season. Of the seven fish that were moribund or that died during transportation, three fish mortalities occurred during the second week of the summer tagging period and four during the final week of the summer tagging period. While the trend suggests seasonal effect may have been a factor, it is not conclusive. The river water (ambient) temperature was elevated by $2.4{ }^{\circ} \mathrm{C}$ between the second and fourth week. The transportation logbooks did not indicate elevated water temperatures relative to ambient water during transportation, nor did they indicate oxygen deprivation on either trip.

Holding juvenile outmigrating salmonids for 30 days resulted in high background mortality rates in all treatments, hampering our ability to determine the tag effects or effects of tagging. The overall 
mortalities ranged from 45 to $72 \%$ for $\mathrm{YCH}, 55$ to $83 \%$ for $\mathrm{STH}$, and 56 to $84 \%$ for SYC. YCH and SYC in the Tagged treatment groups (AT and PIT tags) had significantly higher mortality losses than those in either the Control or Sham (PIT tag only) treatment groups. Over the past few years, tag expulsion and burden projects conducted on YCH and SYC from the Columbia River have experienced variable, but often moderate to high background mortalities. For example, Brown et al. (2008) noted that mortality for run-of-river (ROR) SYC (individuals taken from a juvenile bypass system) surgically implanted with AT and PIT tags ranged from $23 \%$ for fish held 21 days to $69 \%$ by day 30 . Similarly, ROR YCH surgically implanted with AT and PIT tags and held 21 days incurred 27\% mortality; however, no mortality was seen among individuals held for 30 days after implantation (Brown et al. 2008). ROR SYC and YCH experienced mean mortality rates of $53.3 \%$ and $11.8 \%$, respectively, for $21-, 30-, 60-$, and 90 -day holding periods (Brown et al. 2008).

Holding time may have more influence on background mortality for outmigrating ROR SYC and $\mathrm{YCH}$ (and likely STH) than temperature and tag burden. Chinook salmon can smolt at temperatures as low as 6 to $7^{\circ} \mathrm{C}$ (Zaugg and McLain 1972), and as high as $20^{\circ} \mathrm{C}$ (Myrick and Cech 2004). Yet, Brown et al. (2008) suggested that tag burden (using a JSATS AT 33\% larger than those used in this study) and water temperature may be the reason for the high mortality rates. ROR SYC studied by Brown et al. (2008) experienced $15 \pm 3.5$ days to mortality, from the day of surgical implantation for fish held 21 days (Brown et al. 2008). ROR YCH incurred 63\% mortality rate by 21 days overall (among surgically implanted AT and PIT tagged, PIT tagged, and control groups), and a mean $10 \pm 1.7$ days to mortality from the day of surgical implantation (Brown et al. 2008). Temperatures ranged from an estimated average of 11.7 to $13.8^{\circ} \mathrm{C}$ for $\mathrm{YCH}$ and 16.3 to $18.2^{\circ} \mathrm{C}$ for SYC. In a similar study, outmigrating SYC and $\mathrm{YCH}$ experienced mortality, regardless of control, PIT, or AT group, ranging from 27.7 to $64.7 \%$ for SYC and 81.7 to $91.7 \%$ for $\mathrm{YCH}$, when held for 32 and 34 days, respectively (mean tag weight $0.6 \mathrm{~g}$; Liedtke et al. 2008). The temperature ranged over $2.3{ }^{\circ} \mathrm{C}$ ( $\max$. temperature $15.5^{\circ} \mathrm{C}$ ) for $\mathrm{YCH}$ and $4.7^{\circ} \mathrm{C}$ (max temperature $20.7^{\circ} \mathrm{C}$ ) for SYC during the experiment (Liedtke et al. 2008).

A plausible factor in the high mortalities associated with this and similar studies is that holding outmigrating salmonids may confuse their physiological processes and timings. Mortality rate in this study varied over time, regardless of temperature and treatment. We know that the process of smoltification is reversible if smolts remain in freshwater too long, or if conditions are not suitable for continued maintenance of hormone and chloride cell levels (Hoar 1988). Increased water temperature is likely a factor that amplifies an underlying decrease in physiological condition from a prolonged holding period, which leads to or further agitates "frustrated smolt" syndrome (Liedtke et al. 2008), which we propose as an analog to "migratory restlessness" syndrome (described as Zugunruhe, a developmental window for optimal bird migration ). Frustrated smolt syndrome, when considering the physiology and behavior associated with Zugunruhe, could be described as smolts moving past or missing their physiological window - a developmental window optimal for migration or a gated annual physiological event (Handeland et al. 2004; McCormick and Saunders 1987; Liedtke et al. 2008) — and being subsequently forced to undergo desmoltification in a state of low-energy and heightened stress (McCormick et al. 1998; Handeland et al. 2004; Zydlewski et al. 2005). For example, if a particular size or physiological threshold, like sexual maturation, is not reached during a seasonal decision window, developmental transition and subsequent timing of migration may be delayed or reversed (Arnesen et al. 2003). Unfortunately, "frustrated smolt" syndrome, the energetics of smolt-parr reversion (Folmar et al. 1982), and survivorship during this process are poorly documented, even though many salmonid 
researchers acknowledge that holding outmigrating salmonids leads to reduced condition and elevated mortalities.

Due to the high background mortality rates, the influence of tag burden on mortality is inconclusive, regardless of treatment. The tag burden for the Tagged treatment group was relatively low $(1.7 \%)$ in the YCH and moderate (4.2\%) in the SYC; it was very low for the STH Tagged and the Sham treatment groups of all species $(0.7 \%)$. The overall mortalities for Tagged, Sham, and Control treatment groups of $\mathrm{YCH}$ were $62 \%, 60 \%$, and $50 \%$, respectively. The mortalities for the SYC were $76 \%, 65 \%$, and $63 \%$, respectively, for the Tagged, Control, and Sham treatment groups. Similar to these results, past studies have found negative effects in the survival of salmonids relative to elevated tag burdens (Welch et al. 2007; Chittenden et al. 2009; Brown et al. 2010). Liedtke et al. (2008) reported the mean tag burden for SYC as $4.1 \%$, with an $83.3 \%$ mortality rate and a YCH mean tag burden of $2.7 \%$ with a $64.7 \%$ overall mortality rate. Brown et al. (2010) reported that the combination of AT and PIT tags had negative effects on juvenile $\mathrm{YCH}$ when tag burdens were greater than 6.7\% (80- to 109-mm FL). Welch et al. (2007) reported juvenile STH (120- to 130-mm FL) exhibited 50\% mortality over 29 weeks when tag burden was greater than $6.7 \%$. Hall et al. (2009) suggested 5.8\% as the maximum tag burden threshold for juvenile outmigrated Chinook salmon (in saline water, $27.5 \%$ ) to minimize the effects on survival.

Tag encapsulation, adhesion, and pressure necrosis were present in some of the necropsied fish, indicating that even though tag burdens were relatively low, the AT and PIT tags still caused irritation and damage. Fish tissue responses varied from a fibrous thin film deposited on and around the tags to partial or near complete encapsulation of the tags along the body wall or the intestinal mesenteries. The AT and PIT tags were often embedded in adipose tissue, pyloric ceacae, wrapped in the spleen, or had migrated toward the vent — events that have also been reported in other fish studies (Moore et al. 1990; Baras and Westerloppe 1999; Gheorghiu et al. 2010). The effects of tag encapsulation, whether short- or long-term, are poorly studied.

Tag loss was relatively low for PIT tags $(0.2$ to $0.4 \%)$ and the AT/PIT-tag combination $(0.12$ to $2.1 \%)$ for fish held 30 days. The losses of AT and PIT tags were higher in this study than in other studies with greater tag burdens and no tag loss (3.1 to 11\%, [Brown et al. 2006] and 7 to 8\% [Chittenden et al. 2009]). Conversely, other studies have shown higher tag losses in salmonids where the tag burdens were the same or slightly greater (LaCroix et al. 2004; Welch et al. 2007). Because there was only one AT lost per species in this study, it is difficult to extrapolate the influence or mechanisms involved with the tag losses. The $4.0 \%$ tag burden may have an influence on the AT loss (by SYC), which had the greater mean tag burden compared to YCH and STH. It should be noted that tag loss may be partly attributed to "surgeon effect" as well. The surgeon with the greatest, standardized tag loss (1.1\%), surgeon B, was the same surgeon that implanted two of the three lost AT and PIT tags, if species was ignored and all fish were pooled together. There were no differences among surgeons for tag loss, because the statistics were conducted by species, rather than for all fish combined. Surgeon effect has occurred in other studies (Panther et al. 2010; Deters et al. 2010), and a recent review of surgeon training highlights the importance of surgical training and performance in telemetry studies (Cooke et al. 2011). As highlighted by Brown et al. (2010), research that examines tag or transmitter implantation will likely have some amount of tag loss regardless of surgeon or tag burden.

While this laboratory-based tag loss and survival study was conducted concurrently with a large tagging effort for a field survival study in an attempt to augment the larger study results, our high, background mortality rates hindered the resulting analyses. This is not a unique problem for juvenile 
outmigrating salmonids held for extended periods in freshwater. Including this study, at least six other investigations (Brown et al. 2006; Welch et al. 2007; Liedtke et al. 2008; Brown et al. 2008; Wargo-Rub et al. 2009) have shown high background mortalities when juvenile outmigrating SYC, YCH, and STH were held for extended periods of time in freshwater. While tag burden and expulsion studies are necessary to monitor the effects of newer technology, we highly recommend that future research develop a more natural exposure to monitor tag effects. We recommend that future research also consider other factors, including swimming ability and predator avoidance, to determine the effects of tags as suggested by Jepsen (Jepsen et al. 2002; Jepsen 2003); specifically, AT- and PIT-implantation and their burden on juvenile salmonids. 


\subsection{References}

Arnesen AM, H Toften, T Agustsson, SO Stefansson, SO Handeland, and BT Bjornsson. 2003. "Osmoregulation, feed intake, growth and growth hormone levels in 0+ Atlantic salmon Salmo salar L. transferred to seawater at different stages of smolt development." Aquaculture 222:167-187.

Anglea SM, DR Geist, RS Brown, KA Deters, and RD McDonald. 2004. "Effects of acoustic transmitters on swimming performance and predator avoidance of juvenile Chinook salmon." North American Journal of Fisheries Management 24(1):162-170.

Baras E and L Westerloppe. 1999. "Transintestinal expulsion of surgically implanted tags by African catfish Heterobranchus longifilis of variable size and age." Transactions of the American Fisheries Society 128(4):737-746.

Brown RS, SJ Cooke, WG Anderson, and RS McKinley. 1999. "Evidence to challenge the 2\% Rule for biotelemetry." North American Journal of Fisheries Management 19:867-871.

Brown RS, DR Geist, KA Deters, and A Grassell. 2006. "Effects of surgically implanted acoustic transmitters $>2 \%$ of body mass on the swimming performance, survival, and growth of juvenile sockeye and Chinook salmon." Journal of Fish Biology 69(6):1626-1638.

Brown RS, KM Carter, KA Deters, DR Geist, GA McMichael, CA McKinstry, and R Easton. 2008. "Evaluation of growth, survival, tag expulsion, and tissue reaction in acoustic-tagged juvenile salmonids." In Comparative Performance of Acoustic-Tagged and PIT-Tagged Juvenile Salmonids. PNNL-16604, prepared for the U.S. Army Corps of Engineers, Portland, Oregon, by Pacific Northwest National Laboratory, Richland, Washington.

Brown RS, RA Harnish, KM Carter, JW Boyd, KA Deters, and MB Eppard. 2010. "An evaluation of the maximum tag burden for implantation of acoustic transmitters in juvenile Chinook salmon."

North American Journal of Fisheries Management 30(2):499-505.

Carlson, Thomas J, et al. In Preparation. Acoustic Telemetry Evaluation of Dam Passage Survival and Associated Metrics at John Day, The Dalles, and Bonneville Dams, 2010. In preparation for the U.S. Army Corps of Engineers, Portland, Oregon, by Pacific Northwest National Laboratory, Richland, Washington.

Chittenden C, K Butterworth, K Cubitt, M Jacobs, A Ladouceur, D Welch, and R McKinley. 2009. "Maximum tag to body size ratios for an endangered coho salmon (O. kisutch) stock based on physiology and performance." Environmental Biology of Fishes 84(1):129-140.

Cooke SJ, CM Woodley, MB Eppard, RS Brown, and JL Nielsen. 2011. “Advancing the surgical implantation of electronic tags in fish: a gap analysis and research agenda based on a review of trends in intracoelomic tagging effects studies." Reviews in Fish Biology and Fisheries 21:127-151

Clemens BJ, SP Clements, MD Karnowski, DB Jepsen, AI Gitelman, and CB Schreck. 2009. "Effects of transportation and other factors on survival estimates of juvenile salmonids in the unimpounded lower Columbia River." Transactions of the American Fisheries Society 138(1):169-188. 
Coutant CC and RR Whitney. 2000. "Fish behavior in relation to passage through hydropower turbines: A review." Transactions of the American Fisheries Society 129(2):351-380.

Deriso RB, MN Maunder, and JR Skalski. 2007. "Variance estimation in integrated assessment models and its importance for hypothesis testing." Canadian Journal of Fisheries and Aquatic Sciences 64(2):187-197.

Deters KA, RS Brown, KM Carter, JM Boyd, MB Eppard, and AG Seaburg. 2010. "Performance assessment of suture type, water temperature and surgeon skill in juvenile Chinook salmon surgically implanted with acoustic transmitters." Transactions of the American Fisheries Society 139:888-899.

Faber DM, MA Weiland, R Moursund, TJ Carlson, N Adams, and D Rhondorf. 2001. Evaluation of the Fish Passage Effectiveness of the Bonneville I Prototype Surface Collector Using Three-Dimensional Ultrasonic Fish Tracking. PNNL-13526, prepared for the U.S. Army Corps of Engineers, Portland, Oregon, by Pacific Northwest National Laboratory, Richland, Washington.

Folmar LC, WW Dickhoff, CVW Mahnken, an FW Waknitz. 1982. Stunting and parr-reversion during smoltification of coho salmon (Oncorhynchus kisutch). Aquaculture 28(1-2):91-104.

Gheorghiu C, J Hanna, JW Smith, DS Smith, and MP Wilkie. 2010. "Encapsulation and migration of PIT tags implanted in brown trout (Salmo trutta L.)." Aquaculture 298:350-353.

Hall JE, J Chamberlin, AN Kagley, C Greene, and KL Fresh. 2009. "Effects of gastric and surgical insertions of dummy ultrasonic transmitters on juvenile Chinook salmon in seawater." Transactions of the American Fisheries Society 138(1):52-57.

Handeland SO, E Wilkinson, B Sveinsbo, SD McCormick, and SO Stefansson. 2004. "Temperature influence on the development and loss of seawater tolerance in two fast-growing strains of Atlantic salmon." Aquaculture 233:513-529.

Hoar WS. 1988. The physiology of smolting salmonids. In Fish Physiology. Hoar WS and DJ Randall (eds), Vol. 11, part B, pp. 275-343. New York: Academic Press.

Jepsen N, K Aarestrup, F Okland, and G Rasmussen. 1998. "Survival of radio-tagged Atlantic salmon (Salmo salar L.) and trout (Salmo trutta L.) smolts passing a reservoir during seaward migration." Hydrobiologia 372:347-353.

Jepsen N, A Koed, EB Thorstad, and E Baras. 2002. "Surgical implantation of telemetry transmitters in fish: How much have we learned?" Hydrobiologia 483(1-3):239-248.

Jepsen N. 2003. "Long-term retention of surgically implanted radio transmitters in pikeperch." Journal of Fish Biology 63:260-262.

Lacroix GL, D Knox, and P McCurdy. 2004. "Effects of implanted dummy acoustic transmitters on juvenile Atlantic salmon." Transactions of the American Fisheries Society 133(1):211-220. 
Liedtke TL, LP Gee, MG Mesa, JW Beeman, DG Elliot, CM Conway. 2008. Evaluation of predator avoidance ability, tag loss, and tissue response of acoustic-tagged juvenile salmonids. In Comparative Performance of Acoustic-Tagged and PIT-Tagged Juvenile Salmonids. PNNL-16604, prepared for the U.S. Army Corps of Engineers, Portland, Oregon, by Pacific Northwest National Laboratory, Richland, Washington.

Lucas MC. 1989. "Effects of implanted dummy transmitters on mortality, growth and tissue reaction in rainbow trout, Salmo gairdneri, Richardson." Journal of Fish Biology 35(4):577-587.

Markus HC. 1933. "The effects of tags upon fresh water fishes." Transactions of the American Fisheries Society 63(1):319-325.

Martinelli TL, HS Hansel, and RS Shively. 1998. "Growth and physiological responses to surgical and gastric radio transmitter implantation techniques in subyearling Chinook salmon (Oncorhynchus tsawytscha)." Hydrobiologia 371/372:79-87.

Marty GD and RC Summerfelt. 1986. "Pathways and mechanisms for expulsion of surgically implanted dummy transmitters from channel catfish." Transactions of the American Fisheries Society 115(4):577589.

McComas RL, D Frost, SG Smith, JW Ferguson, TJ Carlson, and T Aboellail. 2005. A Study to Estimate Salmonid Survival Through the Columbia River Estuary Using Acoustic Tags, 2002. Report to the U.S. Army Corps of Engineers, Portland, Oregon. Contract \#E86910060, National Oceanic and Atmospheric Administration - National Marine Fisheries Service, Northwest Fisheries Science Center, Seattle, Washington.

McCormick SD and RL Saunders. 1987. "Preparatory physiological adaptations for marine life of salmonids: osmoregulation, growth, and metabolism." American Fisheries Society Symposium 1:211229.

McCormick SD, LP Hansen, TP Quinn, and RL Saunders. 1998. "Movement, migration, and smolting of Atlantic salmon (Salmo salar)." Canadian Journal of Fisheries and Aquatic Sciences 55(Suppl. 1):77-92.

McCormick SD, DT Lerner, MY Monette, K Nieves-Puigdoller, JT Kelly, and BT Björnsson. 2009.

"Taking it with you when you go: How perturbations to the freshwater environment, including temperature, dams, and contaminants, affect marine survival of salmon." American Fisheries Society Symposium 69:195-214.

Moore A, IC Russell, and ECE Potter. 1990. "The effects of intraperitoneally implanted dummy acoustic transmitters on the behavior and physiology of juvenile Atlantic salmon, Salmo salar L." Journal of Fish Biology 37(5):713-721.

Muir WD, SG Smith, JG Williams, and BP Sandford. 2001. "Survival of juvenile salmonids passing through bypass systems, turbines, and spillways with and without flow deflectors at Snake River dams." North American Journal of Fisheries Management 21(1):135-146.

Mulcahy DM. 2003. "Surgical implantation of transmitters into fish.” ILAR Journal 44(4):295-306. 
Myrick CA and JJ Cech Jr. 2004. "Temperature Effects on Chinook Salmon and Steelhead: A Review Focusing on California's Central Valley Populations.” Bay-Delta Modeling Forum, Technical Publication 01-1. Available at: http://www.sfei.org/modelingforum.

(NMFS) National Marine Fisheries Service. 2008. Biological Opinion (BiOp) on the operation of the Federal Columbia River Power System (FCRPS).

Panther JL, RS Brown, GL Gaulke, CM Woodley, and KA Deters. 2010. Influence of Incision Location on Transmitter Loss, Healing, Incision Lengths, Suture Retention, and Growth of Juvenile Chinook Salmon. PNNL-19192, prepared for the U.S. Army Corps of Engineers, District, Portland, Oregon, by Pacific Northwest National Laboratory, Richland, Washington.

Petering RW and DL Johnson. 1991. "Suitability of a cyanoacrylate adhesive to close incisions in black crappies used in telemetry studies." Transactions of the American Fisheries Society 120(4):535-537.

Ploskey GR, MA Weiland, JS Hughes, SR Zimmerman, RE Durham, ES Fischer, J Kim, RL Townsend, JR Skalski, and RL McComas. 2007. Acoustic Telemetry Studies of Juvenile Chinook Salmon Survival at the Lower Columbia Projects in 2006. PNNL-16560, prepared for U.S. Army Corps of Engineers District, Portland, Oregon, by Pacific Northwest National Laboratory, Richland, Washington.

Ploskey GR, MA Weiland, JS Hughes, SR Zimmerman, RE Durham, ES Fischer, J Kim, RL Townsend, JR Skalski, RA Buchanan, and RL McComas. 2008. Survival of Juvenile Chinook Salmon Passing the Bonneville Dam Spillway in 2007. PNNL-18113, prepared for U.S. Army Corps of Engineers, Portland District, Portland, Oregon, by Pacific Northwest National Laboratory, Richland, Washington.

Plumb JM, RW Perry, NS Adams, and DW Rondorf. 2006. “The effects of river impoundment and hatchery rearing on the migration behavior of juvenile steelhead in the lower Snake River, Washington." North American Journal of Fisheries Management 26(2):438-452.

Scruton DA, CJ Pennell, CE Bourgeois, RF Goosney, TR Porter, and KD Clarke. 2007. "Assessment of a retrofitted downstream fish bypass system for wild Atlantic salmon (Salmo salar) smolts and kelts at a hydroelectric facility on the Exploits River, Newfoundland, Canada." Hydrobiologia 582:155-169.

Skalski JR. 1998. "Estimating season-wide survival rates of outmigrating salmon smolt in the Snake River, Washington.” Canadian Journal of Fisheries and Aquatic Sciences 55(3):761-769.

Skalski JR, J Lady, R Townsend, AE Giorgi, JR Stevenson, CM Peven, and RD McDonald. 2001. "Estimating in-river survival of migrating salmonid smolts using radiotelemetry." Canadian Journal of Fisheries and Aquatic Sciences 58(10):1987-1997.

Skalski JR, R Townsend, J Lady, AE Giorgi, JR Stevenson, and RD McDonald. 2002. "Estimating route-specific passage and survival probabilities at a hydroelectric project from smolt radio telemetry studies.” Canadian Journal of Fisheries and Aquatic Sciences 59(8):1385-1393.

Summerfelt RC and LS Smith. 1990. "Anesthesia, surgery, and related techniques." Pages 213-263 in CB Schreck and PB Moyle (eds). Methods for Fish Biology. American Fisheries Society, Bethesda, Maryland. 
Wagner GN, ED Stevens, and P Byrne. 2000. "Effects of suture type on surgical wound healing in rainbow trout." Transactions of the American Fisheries Society 129(5):1196-1205.

Wargo-Rub AM, RS Brown, BP Sandford, KA Deters LG Gilbreath, MS Myers, ME Peterson, RA Harnish, EW Oldenburg, JA Carter, IW Welch, GA McMichael, JW Boyd, EE Liedtke, and GM Mathews. 2009. Comparative Performance of Acoustic-Tagged and Passive Integrated Transponder-Tagged Juvenile Salmonids in the Columbia and Snake Rivers, 2007. Prepared for the U.S. Army Corps of Engineers, Portland, Oregon, by Pacific Northwest National Laboratory, Richland, Washington. Contract W66QKZ60441152.

Weiland MA, GR Ploskey, JS Hughes, Z Deng, T Fu, TJ Monter, GE Johnson, F Khan, MC Wilberding, AW Cushing, SA Zimmerman, DM Faber, RE Durham, RL Townsend, JR Skalski, J Kim, ES Fischer, and MM Meyer. 2009. Acoustic Telemetry Evaluation of Juvenile Salmonid Passage and Survival at John Day Dam with Emphasis on the Prototype Surface Flow Outlet, 2008. PNNL-18890, prepared for U.S. Army Corps of Engineers, Portland District, Portland, Oregon, by Pacific Northwest National Laboratory, Richland, Washington.

Welch DW, SD Batten, and BR Ward. 2007. "Growth, survival, and tag retention of steelhead trout (O. mykiss) surgically implanted with dummy acoustic tags.” Hydrobiologia 582:289-299.

Zale AV, C Brooke, and WC Fraser. 2005. "Effects of surgically implanted transmitter weights on growth and survival stamina of small adult Westslope cutthroat trout." Transactions of the American Fisheries Society 134:653-660.

Zaugg WS and LR McLain. 1972. Changes in gill adenosine triphosphatase activity associated with parr-smolt transformation in steelhead trout, coho, and spring Chinook salmon. Journal of the Fisheries Research Board of Canada 29:167-171.

Zydlewski GB, A Haro, and SD McCormick. 2005. "Evidence for cumulative temperature as an initiating and terminating factor in downstream migratory behavior of Atlantic salmon (Salmo salar) smolts." Canadian Journal of Fisheries and Aquatic Sciences 62:68-78. 



\section{Distribution}

No. of

Copies

1 Offsite Distribution

M. Brad Eppard

US Army Corps of Engineers

PO Box 2946

333 SW $1^{\text {st }}$ Ave, Robert Duncan Plaza

Portland, OR, 97208-2946
No. of

\section{Copies}

9 Onsite Distribution

Pacific Northwest National Laboratory CM Woodley

SEQUIM

Pacific Northwest National Laboratory

KM Carter

K6-85

KA Wagner

K3-61

J Kim

K6-85

RS Brown

K6-85

Pacific Northwest National Laboratory

IM Royer

MA Weiland

SM Carpenter

MB Gay
North Bonneville

North Bonneville

North Bonneville

North Bonneville 




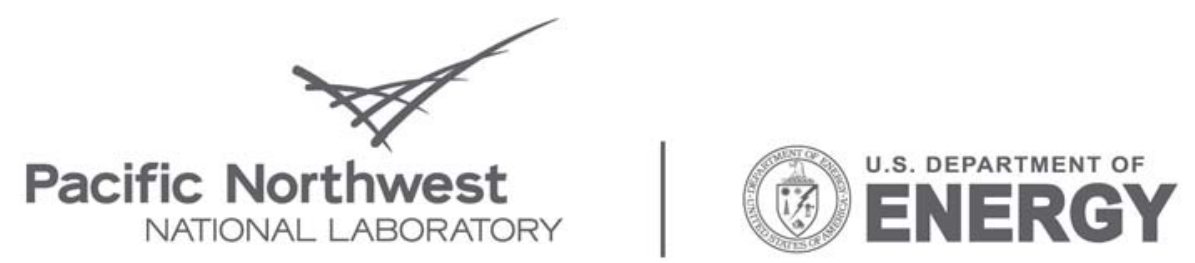

Proudly Operated by Battelle Since 1965

902 Battelle Boulevard

P.O. Box 999

Richland, WA 99352

1-888-375-PNNL (7665)

www.pnl.gov 
Filename: 2010TagExpulsion_Final_20111020.doc

Directory: $\quad$ C: $\quad$ Documents and Settings $\backslash$ D3h082\My Documents

Template: $\quad$ C:LDocuments and Settings\d3a753 $\backslash$ My

Title:

Documents $\backslash E T D \backslash$ Woodley $\backslash 2011 \backslash 2010$ Tag Expulsion Draft_012611_SKE.dot

Subject:

Author:

Christa Woodley

Keywords:

Comments:

Creation Date: $\quad$ 10/20/2011 10:26:00 PM

Change Number: $\quad 2$

Last Saved On: $\quad$ 10/20/2011 10:26:00 PM

Last Saved By: Christa Woodley

Total Editing Time: 0 Minutes

Last Printed On: $\quad$ 10/21/2011 9:13:00 AM

As of Last Complete Printing

Number of Pages: 56

Number of Words: 12,940 (approx.)

Number of Characters: $\quad 73,760$ (approx.) 